\title{
Experimental Study on Bubble Dynamics and Wall Heat Transfer Arising from a Single Nucleation Site at Subcooled Flow Boiling Conditions - Part 2: Data Analysis on Sliding Bubble Characteristics and Associated Wall Heat Transfer
}

\author{
Junsoo Yoo ${ }^{\mathrm{a},}$, Carlos E. Estrada-Perez ${ }^{\mathrm{b}}$, Yassin A. Hassan ${ }^{\mathrm{b}, \mathrm{c}}$ \\ ${ }^{a}$ Idaho National Laboratory, 2525 North Fremont Ave., P.O.Box 3860, Idaho Falls, ID, USA (Zip: 83415-3870) \\ ${ }^{b}$ Department of Mechanical Engineering, Texas A\&M University, 100 MEOB, College Station, TX , USA (Zip: 77843-3123) \\ ${ }^{c}$ Department of Nuclear Engineering, Texas A\&M University, 253 Bizzell West, College Station, TX, USA (Zip: 77843-3133) \\ *Corresponding author: Tel. +1 208-526-2024; Email address: kaks2000@gmail.com (J. Yoo)
}

\begin{abstract}
This second of two companion papers presents an analysis of sliding bubble and wall heat transfer parameters measured during subcooled boiling in a square, vertical, upward flow channel. Bubbles were generated only from a single nucleation site for better observation of both the sliding bubble characteristics and their impact on wall heat transfer through optical measurement techniques. Specific interests include: (i) bubbles departure and subsequent growth while sliding, (ii) bubbles release frequency, (iii) coalescence of sliding bubbles, (iv) sliding bubbles velocity, (v) bubbles size distribution and (vi) wall heat transfer influenced by sliding bubbles.

The results showed that sliding bubbles involve two distinct growth behaviors: (i) at low mass fluxes, sliding bubbles grew fast near the nucleation site, subsequently shrank, and then grew again, (ii) as mass flux increased, however, sliding bubbles grew more steadily. The bubbles originating from the single nucleation site coalesced frequently while sliding, which showed close relation with bubbles release frequency. The sliding bubble velocity near the nucleation site consistently decreased by increasing mass flux, while the observation often became reversed as the bubbles slid downstream due to the effect of interfacial drag. The sliding bubbles moved faster than the local liquid (i.e., $\mathrm{u}_{\mathrm{r}}<0$ ) at low mass flux conditions, but it became reversed as the mass flux increased. The size distribution of sliding bubbles followed Gaussian distribution well both near and far from the nucleation site. The standard deviation of bubble size varied insignificantly through sliding compared to the changes in mean bubble size.
\end{abstract}


Lastly, the sliding bubbles enhanced the wall heat transfer and the effect became more noticeable as inlet subcooling/mass flux decreased or wall heat flux increased. In particular, the sliding bubble characteristics such as bubble growth behavior observed near the nucleation site played a dominant role in determining the ultimate level of wall heat transfer enhancement within the test channel.

Key words: Subcooled flow boiling, single nucleation site, bubble sliding, bubble coalescence, sliding bubble velocity, bubble size distribution, boiling heat transfer

\section{Introduction}

The enhancement in wall heat transfer caused by boiling and its underlying mechanism has been a topic of great interest within heat transfer community over the last decades. In particular, forced convective boiling, the focus of this paper, is frequently encountered in various industrial applications such as cooling channels and evaporators of engineered systems. However, the mechanism of enhancing wall heat transfer due to the boiling bubbles is yet to be fully understood, and achieving accurate prediction of the process still remains a challenge due to the lack of knowledge about the basic principles.

Recently, advances in computing power and high-speed visualization techniques have made it possible to investigate more detailed features of two-phase flow during boiling process. Consequently, experimental efforts have recently been made to observe fundamental features of boiling which could hardly be captured before. This has opened up the possibility of utilizing mechanistic models which are expected to have more generality in application than previous empirical correlations. Among others, Kurul and Podowski's model (1990) has been one of the most used until recently to mechanistically treat the wall nucleation process. This model basically employed the wall heat flux partitioning concept of Bowring (1962), in which three subcomponents are included to represent the total wall heat flux $\left(\mathrm{q}_{\mathrm{w}}\right)$ : single-phase convection $\left(\mathrm{q}_{1 \varnothing}\right)$, quenching (or transient conduction, $\left.\mathrm{q}_{\mathrm{Q}}\right)$, and evaporation $\left(\mathrm{q}_{\mathrm{e}}\right)$. Kurul and Podowski (1990) used $\mathrm{q}_{\mathrm{Q}}$ as defined in Delvalle and Kenning (1985) while $\mathrm{q}_{\mathrm{e}}$ is calculated by the relation given by Bowring (1962). In order for this mechanistic model to possess high confidence in its predictive ability, the fundamental bubble parameters (or wall nucleation parameters) used to calculate each subcomponent should be well-defined, and this is where experimental insight is required. In general, the bubble departure/lift-off diameter 
(Chu et al., 2011; Klausner et al., 1993; Situ et al., 2005), bubble departure frequency (Euh et al., 2010; Situ et al., 2008), and active nucleation site density (Hibiki and Ishii, 2003) are the parameters commonly used to determine the wall heat flux components $\mathrm{q}_{\mathrm{e}}$ and $\mathrm{q}_{\mathrm{Q}}$. However, Kurul and Podowski 's model (1990) covers only the boiling process at a nucleation site. To properly address the effect of vapor bubbles in forced convective boiling, the bubble and wall heat transfer characteristics beyond a nucleation site must be figured out and modelled as well.

Compared to the researches on bubble behaviors at a nucleation site (e.g., nucleation, bubble growth and departure), bubble behavior after departure from a nucleation site such as bubble sliding have been relatively less explored in experimental studies of forced convective boiling to date. Nevertheless, several authors have reported that such bubble motion can substantially influence wall heat transfer characteristics in flow boiling system. Cornwell (1990) measured the wall heat transfer of the forced convective boiling of R-113 in a tube bundle. He supposed that the total heat transfer is determined by three mechanisms: liquid forced convection, nucleation, and sliding bubbles. The relative significance of each mechanism depended on heat flux conditions as well as locations within the tube. Cornwell (1990) argues that, in the presence of bubbly flow, the sliding bubbles downstream in the tube contributed significantly to the wall heat transfer. Thorncroft et al. (1998) observed a significant difference in bubble dynamics between the boiling experiments of vertical upward and downward flows. In upward flows, the bubbles departing from the nucleation site typically slid along the heater without lift-off; whereas, in downward flows, the bubbles lifted off directly from the nucleation site or lifted off after sliding. From the observation of larger heat transfer coefficients for upward flow compared to those for downward flow under identical experimental conditions, Thorncroft et al. (1998) deduced that such increases in wall heat transfer for the upward flow result from the bubble sliding behavior. Regarding this, further experimental evidence was provided by Thorncroft and Klausner (1999), in which the turbulence enhancement of the bulk liquid was considered the main mechanism for the increase in wall heat transfer caused by sliding bubbles. A similar observation was also made by Houston and Cornwell (1996); they argued that the effect of increasing turbulence caused by sliding bubbles is more significant within a narrow channel than in an ordinary sized channel.

The above mentioned studies revealed the significance of sliding bubble motion on wall heat transfer in a forced convective boiling system and have subsequently inspired further research employing high-speed visualization techniques. Okawa et al. (2005) observed the rise characteristics of bubbles after departure from a nucleation site in a vertical upward subcooled flow boiling tube. Three different bubble rise characteristics were 
observed, which included (i) bubbles sliding for a long distance, (ii) bubbles lifting-off from the heater surface after sliding a few millimeters, and (iii) bubbles lifting off but subsequently reattaching to the heater surface. Okawa et al. (2005) proposed that the bubble lift-off is mainly attributable to the bubble shape deformation. Yuan et al. (2011) studied the effects of pressure on bubble dynamics during a subcooled flow boiling experiment in a vertical rectangular narrow channel. The bubble behavior captured by a high-speed camera (HSC) showed that pressure had a significant effect on bubble growth, lift-off, and sliding. Under lower pressure, bubbles growing at the nucleation site lifted off directly from the heater wall and collapsed without sliding. In contrast, bubbles under higher pressure kept growing while sliding along the heater wall even after the bubbles left (or departed from) the nucleation site. They also found that sliding bubble velocity as well as sliding distance was significantly affected by the bubble growth rate while sliding. Xu et al. (2013) observed sliding bubble dynamics in the vertical upward flow of a narrow channel. Several sliding bubble parameters such as bubble shape, bubble growth, and bubble velocity after departing from the nucleation site, were investigated. They found that the contact angles of the bubbles hardly changed during the sliding motion, and the sliding bubble velocity showed a proportional relation to the bubble diameter and liquid flow rate. Similarly, Li et al. (2013) investigated the bubble sliding behavior in subcooled boiling flow in a vertical narrow channel. The parameters of main interest were the bubble number, bubble size, and sliding bubble velocity. In particular, they studied both the mean and the statistical distribution of such parameters under different experimental conditions. According to them, the bubble size distribution depended significantly on the inlet subcooling and was less affected by the wall heat flux. They also found that the distribution of the sliding bubble velocity followed the normal distribution and the mean velocity increased when the inlet subcooling decreased.

However, despite the above-mentioned efforts, the experimental insight into sliding bubble characteristics in subcooled boiling flow are still lacking, and the mechanism of enhancing wall heat transfer due to sliding bubbles is not understood well. In this respect, we investigated sliding bubbles behavior and their impact on wall heat transfer through subcooled flow boiling experiments. In particular, to better understand the underlying physics, bubbles behavior arising from a single nucleation site was observed with both micro- and macroscopic views from high-speed cameras while the heater surface temperature was measured with an infrared (IR) camera. Also, the 
images were taken strategically to ensure reliable statistics of the measured data. Details of the experimental strategy, image acquisition/analysis, data quality achieved, and associated uncertainty are described in Part 1 paper ${ }^{\mathbf{A}}$.

This second of two companion papers presents an analysis of bubble and wall heat transfer parameters measurement during the present work. In most cases, bubbles departing from the single nucleation site slid along the heater surface until they exit the test section except for a moment of bouncing just after the departure. Also, the thermal data taken by IR camera revealed that such sliding bubbles originating from the single nucleation site caused a significant increase in wall heat transfer compared to the single-phase forced convection. For a deeper insight into the mechanism, we observed the sliding bubble characteristics in various aspects. In particular, the effects of liquid subcooling, mass flux and wall heat flux on such characteristics were extensively investigated, and then the experimental evidence associated with the enhanced wall heat transfer is discussed.

2. Experimental setup, test conditions, and research scope

2.1. Flow boiling loop, test section design and cameras arrangement

The present subcooled flow boiling experiment was performed in a vertical, square, upward flow channel at atmospheric pressure. As working fluid, HFE-301 (Novec ${ }^{\mathrm{TM}} 7000$, 3M Inc.) was used, the physical properties of which are given in Table 1. Overall, the loop was designed to have an entrance length $l / \mathrm{D}_{\mathrm{h}} \approx 61$ for the flow to be hydro-dynamically fully developed before entering the test section ( $l$ is the channel length prior to the test section and $\mathrm{D}_{\mathrm{h}}$ is the hydraulic diameter of the square channel).

The test section was $305 \mathrm{~mm}$ long with flow area $10 \times 10 \mathrm{~mm}^{2}$ inside. Three sides of the test section walls were made of transparent acrylic and a heater wall was installed on the remaining side as shown in Figure 1. The total heated area was $7.5 \times 224 \mathrm{~mm}^{2}$ with total heated length $\mathrm{L}_{0}=224 \mathrm{~mm}$ along the flow path, in which a single artificial nucleation site was placed at the axial location $\mathrm{L} / \mathrm{L}_{0} \approx 0.41$ (see Figure 1). Note that $\mathrm{L} / \mathrm{L}_{0}$ denotes the relative axial location within $\mathrm{L}_{0}$ (i.e., $0 \leq \mathrm{L} \leq \mathrm{L}_{0}$ ), the definition of which is consistently used throughout this paper. The heater wall consisted of multiple layers, i.e., polyimide tape, ITO (indium-tin-oxide) film, glass substrate and sapphire window, all of which are transparent to visible light. Among them, ITO film ( 700 nm thick) was used as heating element to provide heat into the channel through Joule heating ${ }^{\mathrm{A}}$.

\footnotetext{
${ }^{\text {A }}$ Yoo,J, Estrada-Perez, C.E., Hassan, Y.A., Experimental Study on Bubble Dynamics and Wall Heat Transfer Arising from a Single Nucleation Site at Subcooled Flow Boiling Conditions - Part 1: Experimental Methods and Data Quality Verification (Under review); This footnote will be removed and references/citations will be updated once the volume \& issue number is assigned for this article after the review process.
} 
Three high-speed cameras and one IR camera were used to observe the bubble and wall heat transfer characteristics, respectively (see Figure 1). High-speed camera (HSC) 1 captured detailed bubbles motion near the nucleation site with high resolutions $(10 \mathrm{kHz}, 9.09 \mu \mathrm{m})$ while HSC 3 captured bubbles motion over a larger area of flow path with relatively limited resolutions $(0.5 \mathrm{kHz}, 78.7 \mu \mathrm{m})$. Meanwhile, bubbles behavior outside the views of HSC 1 and HSC 3 were also observed by HSC $2(1 \mathrm{kHz}, 21.4 \mu \mathrm{m})$. The numerous bubble images obtained by HSC 1 and HSC 3 were analyzed to characterize the bubbles behavior with reliable statistics, while HSC 2 was only used to qualitatively describe the bubbles motion downstream in the test channel. Besides, the heater surface (hereafter, wall) temperature in contact with the fluid was captured by an IR camera, for which a calibration procedure described in Yoo et al. (2015) and steady-state heat conduction equation were employed. More details on the experimental method, measurement procedure, image analysis, and data quality achieved are provided in Part 1 of this study ${ }^{\mathrm{A}}$.

Table 1. Physical property of HFE-301 (at $25^{\circ} \mathrm{C}, 1 \mathrm{~atm}$ )

\begin{tabular}{l|c}
\hline Liquid density $\left(\mathrm{kg} / \mathrm{m}^{3}\right)$ & 1,400 \\
\hline Boiling point $\left({ }^{\circ} \mathrm{C}\right)$ & 34 \\
\hline Kinematic viscosity $(\mathrm{cSt})$ & 0.32 \\
\hline Thermal conductivity $(\mathrm{W} / \mathrm{m} / \mathrm{K})$ & 0.075 \\
\hline Specific heat $(\mathrm{J} / \mathrm{kg} / \mathrm{K})$ & 1,300 \\
\hline Latent heat of vaporization $(\mathrm{kJ} / \mathrm{kg})$ & 142 \\
\hline Surface tension $(\mathrm{N} / \mathrm{m})$ & $12.4 \times 10^{3}$ \\
\hline
\end{tabular}




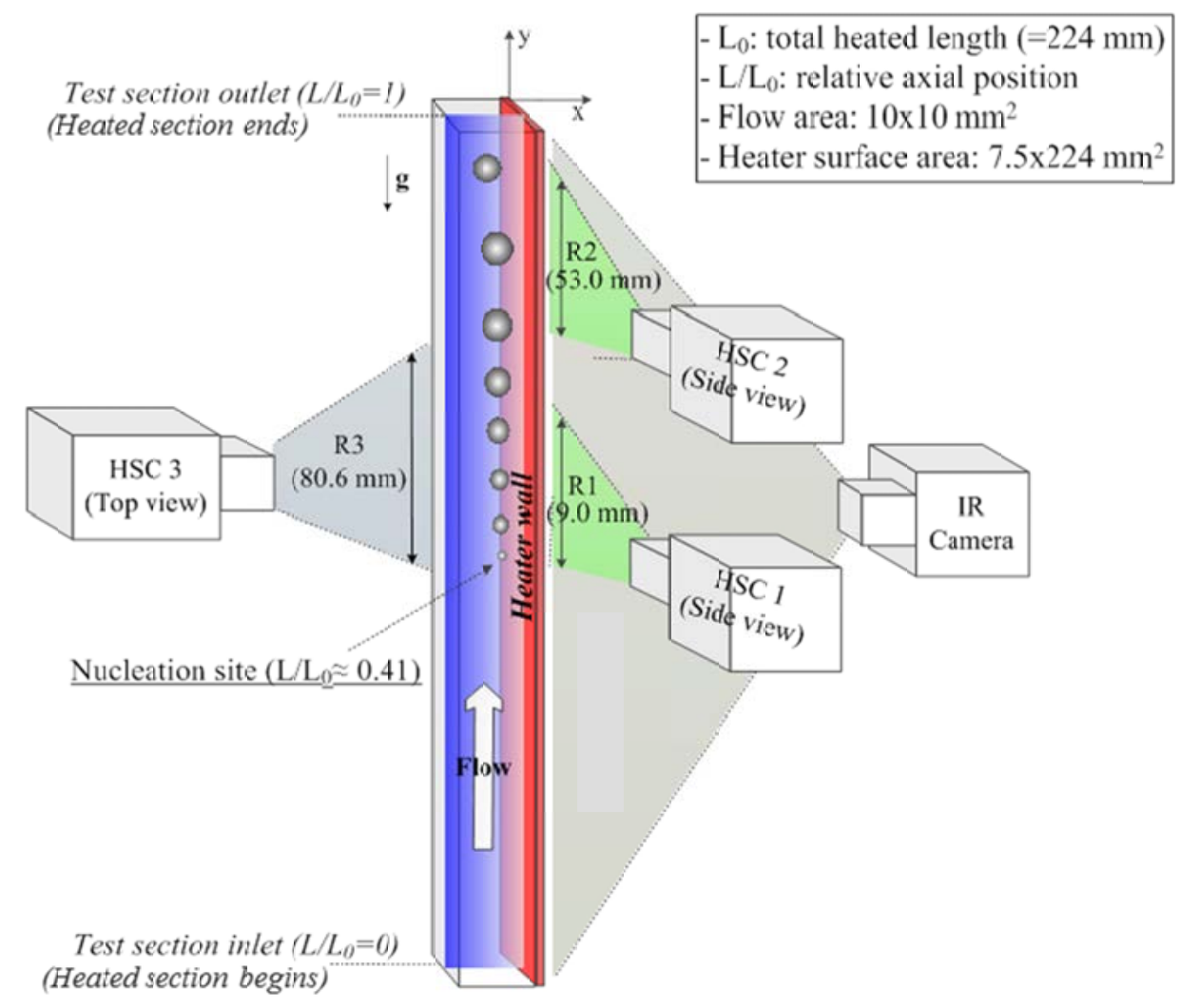

Figure 1. Cameras arrangement around the transparent test section

2.2. Test conditions involving a single nucleation site

The present experiment was performed at atmospheric pressure within ranges of mass flux (G), wall heat flux $\left(\mathrm{q}_{\mathrm{w}}\right)$, and inlet subcooling $\left(\Delta \mathrm{T}_{\text {sub,in }}\right)$ of about $140 \sim 700 \mathrm{~kg} / \mathrm{m}^{2} \mathrm{~s}, 8 \sim 35 \mathrm{~kW} / \mathrm{m}^{2}$, and $4.5 \sim 13.6{ }^{\circ} \mathrm{C}$, respectively. The specific test conditions are summarized in Table 2. Also, as discussed before, only a single active nucleation site was purposely kept within the entire heated area $\left(7.5 \times 225 \mathrm{~mm}^{2}\right)$ at predefined axial position $\mathrm{L} / \mathrm{L}_{0} \approx 0.41$ (see Figure 1). This minimized the phenomenological complexity induced by boiling and the difficulties of visual observation. The test conditions in Table 2 were chosen to systematically observe the parametric effect of inlet subcooling $\left(\Delta \mathrm{T}_{\text {sub,in }}\right)$, mass flux $(\mathrm{G})$ and wall heat flux $\left(\mathrm{q}_{\mathrm{w}}\right)$. 
Table 2. Summary of test conditions

\begin{tabular}{cccccc}
\hline Exp. No. & $\begin{array}{c}G \\
\left(\mathrm{~kg} / \mathrm{m}^{2} \mathrm{~s}\right)\end{array}$ & $\begin{array}{c}q_{w} \\
\left(\mathrm{~kW} / \mathrm{m}^{2}\right)\end{array}$ & $\begin{array}{c}\Delta T_{\text {sub,in }} \\
(\mathrm{K})\end{array}$ & $J a^{a}$ & $\begin{array}{c}f_{b, 0}{ }^{b} \\
{[\mathrm{~Hz}]}\end{array}$ \\
\hline 1 & 140 & 9.7 & 13.5 & 34.1 & 159 \\
2 & 140 & 11.6 & 13.6 & 42.8 & 163 \\
3 & 140 & 8.1 & 13.5 & 24.1 & 152 \\
4 & 280 & 11.9 & 13.5 & 19.8 & 133 \\
5 & 420 & 12.2 & 13.5 & 6.3 & 239 \\
6 & 420 & 20.4 & 13.5 & 30.6 & 148 \\
7 & 420 & 23.7 & 13.5 & 39.5 & 282 \\
8 & 420 & 17.1 & 13.5 & 20.6 & 139 \\
9 & 560 & 24.0 & 13.6 & 24.2 & 207 \\
10 & 700 & 24.2 & 13.5 & 14.6 & 331 \\
11 & 700 & 30.9 & 13.5 & 27.1 & 343 \\
12 & 700 & 35.1 & 13.5 & 34.9 & 523 \\
13 & 700 & 26.4 & 13.6 & 18.4 & 295 \\
14 & 140 & 9.5 & 4.50 & 49.1 & 135 \\
15 & 420 & 20.1 & 4.50 & 45.8 & 380 \\
16 & 700 & 30.5 & 4.50 & 42.6 & 769 \\
\hline
\end{tabular}

${ }^{a}$ Jacob number at the elevation of nucleation site (estimated based on the average wall temperature measured at $L / L_{0} \approx 0.41$ )

${ }^{b}$ Bubble release frequency (discussed in section 3.2.1)

\subsection{Research scope}

The experimental setup shown in Figure 1 allows us to measure a variety of bubble and wall heat transfer parameters in subcooled boiling flow. The main interests in this paper include: (i) bubbles departure and subsequent growth while sliding, (ii) bubble release frequency, (iii) coalescence of sliding bubbles, (iv) sliding bubbles velocity, (v) size distribution of sliding bubbles and (vi) wall heat transfer influenced by sliding bubbles.

3. Experimental results and discussion

3.1. Bubbles departure and subsequent growth while sliding

3.1.1. Qualitative analysis of bubbles growth behavior

During this study, the boiling at the single nucleation site mostly belonged to a non-isolated (or interference) bubble regime (Zuber, 1963), meaning that the boiling bubbles interfered with each other before departing from the nucleation site due to the fast-occurring boiling process. Consequently, the bubbles grew fast at the nucleation site due to both evaporation and coalescence. After this initial growth, the bubbles typically experienced the following process: (i) departure and subsequently detaching from the wall, (ii) condensing into a smaller sized bubble, (iii) reattaching to the wall, and (iv) sliding in the upward flow direction. Thereafter, the bubbles were largely found to 
slide along the wall until they passed the outlet of test section, which was observed by HSC 2 installed downstream in the test channel as shown in Figure 1. It is noted that we distinguish the concept of bubble lift-off (Klausner et al., 1993) which does not consider a bubble reattachment to the wall from that of the bouncing motion of bubbles (i) (iii) observed in this study. Within the present set of experiments in Table 2, bubble lift-off was observed only in two test cases, namely Exp. No. 14 and 16.

Figure 2 shows the typical bubble motion observed nearby the nucleation site under various subcooled flow boiling conditions. The images were originally taken by the high-resolution camera HSC 1. Figure 2 clearly show the differences in boiling behaviors influenced by changes in inlet subcooling $\left(\Delta \mathrm{T}_{\text {sub,in }}\right.$, Figure 2 top), mass flux ( $\mathrm{G}$, Figure 2 middle), and wall heat flux ( $\mathrm{q}_{\mathrm{w}}$, Figure 2 bottom). On the top left of the Figure 2, we can see that bubble size increased significantly as $\Delta \mathrm{T}_{\text {sub,in }}$ decreased from 13.5 to $4.5^{\circ} \mathrm{C}$. On the other hand, the top right of Figure 2 (parametric study of $\Delta \mathrm{T}_{\text {sub,in }}$ at higher $\mathrm{G}$ and $\mathrm{q}_{\mathrm{w}}$ condition) shows that the effect of varying $\Delta \mathrm{T}_{\text {sub,in }}$ on bubble size was less significant. Bouncing motion of bubbles after departure from the nucleation site became more noticeable when decreasing $\Delta \mathrm{T}_{\text {sub,in }}$, and bubbles were generated and released from the nucleation site more frequently at lower $\Delta \mathrm{T}_{\text {sub,in }}$ conditions. Additionally, by observing the bubbles' trajectory through the test channel from the top of bubbles (top view) using HSC 3 (see Figure 1), it was found that the area swept by sliding bubbles increased by decreasing $\Delta \mathrm{T}_{\text {sub,in }}$. The middle section of Figure 2 shows the effects of $\mathrm{G}$ on bubbles' behavior near the nucleation site. Clearly, the bubbles' growth became significantly restricted as $\mathrm{G}$ increased at constant $\Delta \mathrm{T}_{\text {sub,in }}$ and $\mathrm{q}_{\mathrm{w}}$ conditions. Also, the bouncing motion of bubbles near the nucleation site was reduced as G increased. The bottom of Figure 2 shows that bubbles' bouncing motion became more noticeable as $\mathrm{q}_{\mathrm{w}}$ increased. All these observations commonly imply that the bouncing motion of bubbles near the nucleation site tended to increase at the test conditions causing an increase in wall temperature (i.e., at higher $\mathrm{q}_{\mathrm{w}}$ or lower $\Delta \mathrm{T}_{\text {sub,in }} / \mathrm{G}$ conditions). 


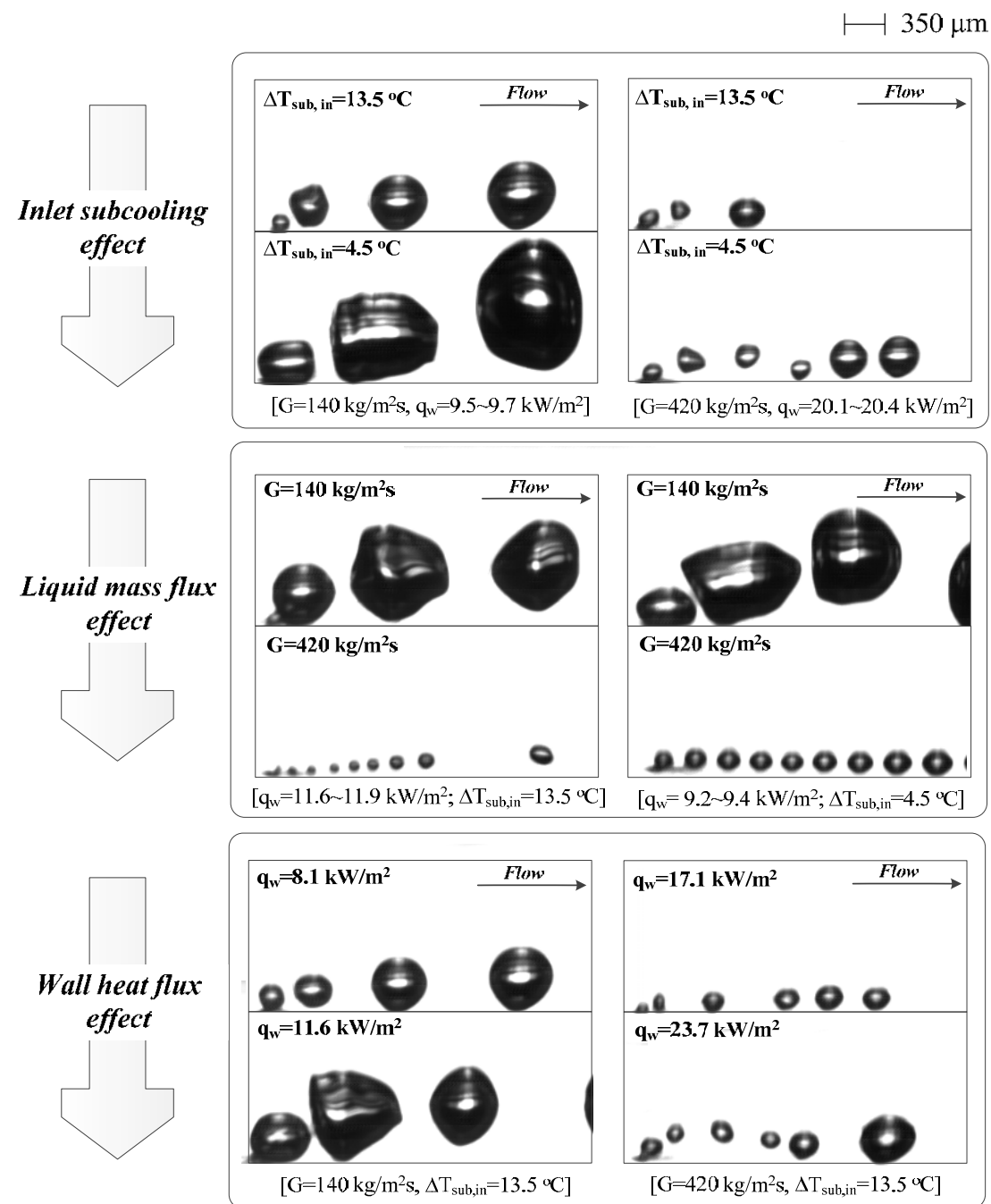

Figure 2. Bubble behaviors at a single nucleation site affected by the varying inlet subcooling (top), mass flux (middle), and wall heat flux (bottom)

Bubbles' bouncing motion was observed by previous researchers as well like Prodanovic et al. (2002) and Okawa et al. (2005). Prodanovic et al. (2002) argued that abrupt change in bubble size and/or bubble shape caused bubbles to detach from heated wall while Okawa et al. (2005) considered that the inertia of flowing liquid toward bubble base during the shape deformation is the main cause of detachment. It is noted that the bubbles in Figure 2 show more irregular deformation compared to those observed by Okawa et al. (2005) and Prodanovic et al. (2002) especially at the test cases involving more bouncing bubbles; and such irregular deformation seems to be caused by successive interaction among bubbles like coalescence near the nucleation site. However, despite the difference in the specific bubble shape, the close relation between the bubble shape deformation and the bubble detachment seems to be common with the previous observation. In addition, the bubble shape deformation tended to be similar with 
that observed by Okawa et al. (2005) in the sense that the bubble shape changed from low to high aspect ratio (i.e., from flattened to elongated bubble shape) while detaching from the wall which was more noticeable for larger bubbles. Therefore, considering Okawa et al.(2005)'s reasoning, it is inferred that the flowing liquid had more chances to access the bubbles' base at the test conditions of higher wall temperature because the bubbles' shape varied more significantly in those cases as shown in Figure 2; and this is why the bouncing motion of bubbles became more noticeable by decreasing $\Delta \mathrm{T}_{\text {sub,in }} / \mathrm{G}$ or by increasing $\mathrm{q}_{\mathrm{w}}$. Also, considering forces driving the bubbles' motion normal to the wall, it is noted that there are several studies to reveal that the bubble shape deformation affects the direction of lift force acting on a bubble (Hibiki and Ishii, 2007; Takagi, 1995; Tomiyama, 2004).

As for the re-attachment of bouncing bubbles to the wall, we suppose it is related to both the abrupt decrease in bubble size and the shape deformation while staying away from the wall because they may change the direction of lift force after the detachment; but further investigation is needed about this.

\subsubsection{Quantitative analysis of sliding bubbles' growth behavior}

Bubble growth while sliding in vertical upward flow boiling has been reported in literature (Li et al., 2013; Okawa et al., 2005; Prodanovic et al., 2002). However, the observed behaviors are quite different among different authors, and the mechanism is still barely known due to the lack of systematic experimental observations. For this reason, in many CFD works Zuber's model (1963) developed for bubble growth in pool boiling is still used for flow boiling simulations (Bae et al., 2010; Yeoh et al., 2008) or the growth of sliding bubbles is often not explicitly addressed (Cheung et al., 2014; Krepper and Rzehak, 2011). Therefore, efforts are still required to overcome these shortcomings, for which we investigated the growth behavior of sliding bubbles. The experimental results were obtained by analyzing a large sample of bubble images captured with HSC 1 and HSC 3, allowing us to better characterize the typical growth behavior of sliding bubbles along the flow path (HSC 2 was only used to qualitatively describe bubbles motion downstream in the test channel).

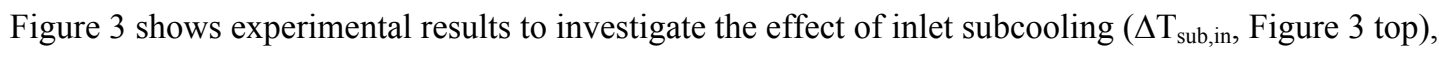
mass flux (G, Figure 3 middle) and wall heat flux ( $\mathrm{q}_{\mathrm{w}}$, Figure 3 bottom) on bubbles growth behavior. Results from HSC 1 for detailed bubble motion near the nucleation site $\left(0.41<\mathrm{L} / \mathrm{L}_{0}<0.45\right)$ are shown on the left, while results from HSC 3 for a longer flow path $\left(0.41<\mathrm{L} / \mathrm{L}_{0}<0.75\right)$ are shown on the right. The $y$-axis in Figure 3 denotes the 
average bubble size while the $\mathrm{x}$-axis denotes the axial location. Thus we can directly compare how the typical bubble growth behavior along the flow path was influenced by changes in $\Delta \mathrm{T}_{\text {sub,in }}$ (top), $\mathrm{G}$ (middle) and $\mathrm{q}_{\mathrm{w}}$ (bottom).

As discussed in section 3.1.1, the bubbles observed during this study often bounced (i.e., detached from the wall and subsequently reattached) after rapid growth at the nucleation site before sliding. Due to the bouncing motion, bubbles started condensing and decreasing in size as they detached from the wall. Then, bubbles grew again once they were reattached to the wall. On the left side of Figure 3, the effect of the bouncing motion is shown as a local peak of the bubble size in the near nucleation site region at $\mathrm{L} / \mathrm{L}_{0} \approx 0.41-0.415$ and we call this 'bouncing peak'. This bouncing peak, however, cannot be observed on the plots at the right side of Figure 3 because HSC 3 had relatively limited resolution (both spatial and temporal). 

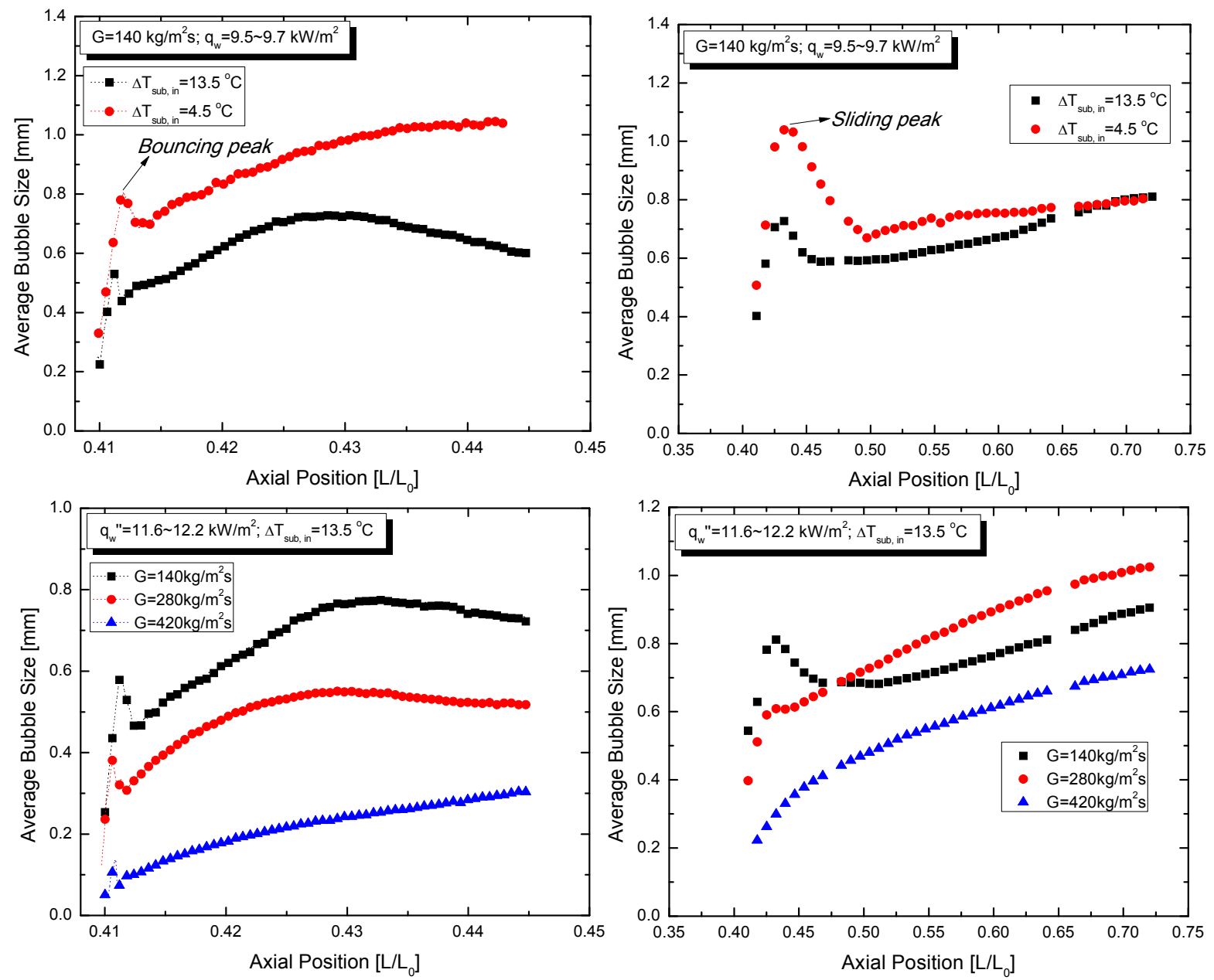

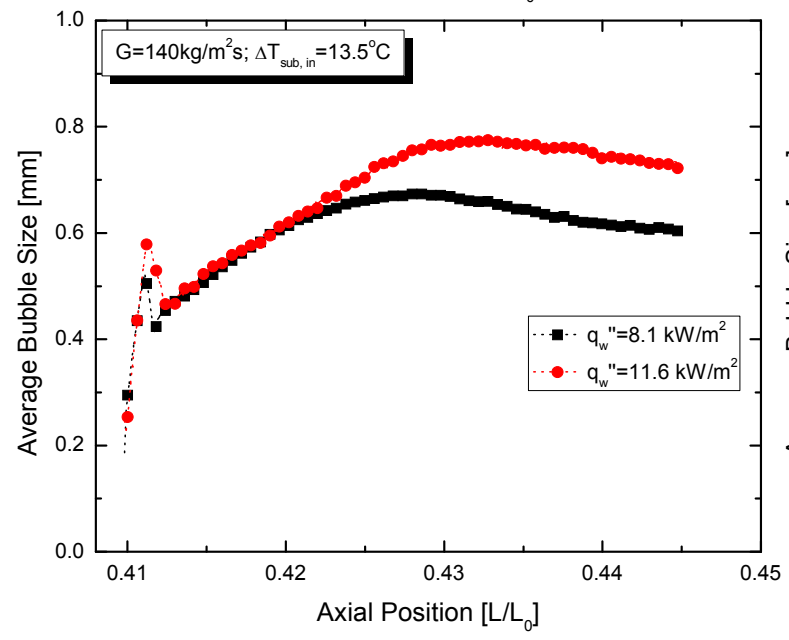

(Observed by HSC 1)

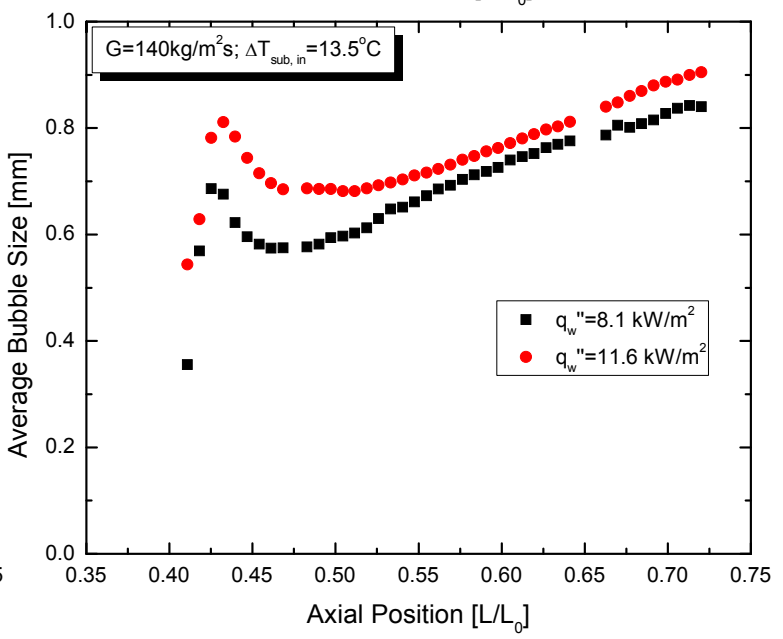

(Observed by HSC 3)

Figure 3. Effects of $\Delta \mathrm{T}_{\text {sub,in }}$ (top), $\mathrm{G}$ (middle), $\mathrm{q}_{\mathrm{w}}$ (bottom) on bubbles growth characteristics along the flow path (left column: observed by HSC 1, right column: observed by HSC 3 ) 
After the bouncing motion, the bubbles typically moved downstream (upward) while attached to the wall, i.e., sliding. On the top left of Figure 3, for the test case of $\Delta \mathrm{T}_{\text {sub,in }}=13.5^{\circ} \mathrm{C}$, the bubble size increases while sliding until reaching to another bubble size peak at about $\mathrm{L} / \mathrm{L}_{0} \approx 0.43$. This peak, what we call 'sliding peak', is also found for the test case of $\Delta \mathrm{T}_{\text {sub,in }}=4.5^{\circ} \mathrm{C}$ at about $\mathrm{L} / \mathrm{L}_{0} \approx 0.44$ which can be seen more clearly on the top right of Figure 3 . These sliding peaks occurred because the sliding bubbles rather condense than evaporate after growing to a certain site due to the lower temperature of the liquid around the bubbles. Also, the top right of Figure 3 shows that the sliding peak is much higher for $\Delta \mathrm{T}_{\text {sub,in }}=4.5^{\circ} \mathrm{C}$ than for $\Delta \mathrm{T}_{\text {sub,in }}=13.5^{\circ} \mathrm{C}$. It is noted that during this study the sliding peak was commonly observed at the test cases of low mass flux $\left(\mathrm{G}=140 \mathrm{~kg} / \mathrm{m}^{2} \mathrm{~s}\right)$. To clarify the reason, we investigated in Figure 4 how the mass flux $(\mathrm{G})$ affected the growth rate of sliding bubbles $(\partial \mathrm{D} / \partial \mathrm{t})$; the sliding bubbles' growth rate was calculated as $\frac{\partial D}{\partial t}=\frac{\partial D}{\partial y} \cdot \frac{\partial y}{\partial t}=\frac{\partial D}{\partial y} \cdot u_{b}\left(\mathrm{u}_{\mathrm{b}}\right.$ is the axial sliding bubble velocity which will be discussed in section 3.3). Figure 4 (left) shows that at low $\mathrm{G}\left(\mathrm{G}=140 \mathrm{~kg} / \mathrm{m}^{2} \mathrm{~s}\right)$ the bubble growth rate decreased sharply 'from positive to negative' after the bubbles departed from the nucleation site and subsequently increased 'from negative to positive' until reaching the 'balanced growth curve' with constant growth rate. Also, it is noted that the 'sliding peak' shown in Figure 3 appeared around the region where the bubble growth rate decreased from positive to negative. The negative bubble growth rate occurred because the sliding bubbles' growth by evaporation was restricted as the bubbles became more exposed to the subcooled liquid while growing. In other words, at low $\mathrm{G}$ the sliding bubbles grew fast initially, and the growing bubbles reached a point where the evaporation and condensation rates were reversed which led to the sliding peak. In contrast, at higher $G(G=700$ $\mathrm{kg} / \mathrm{m}^{2} \mathrm{~s}$ ), shown on the right of Figure 4, the growth rate of sliding bubbles consistently decreased until reaching the constant growth rate without such fluctuation shown on the left of Figure 4 (i.e, decrease to negative value and subsequent increase). As a result, no sliding peak was found for those cases as shown in Figure 5 (middle right).

On the top right of Figure 3, we can also see that the average bubble size grew less along the flow direction at $\mathrm{L} / \mathrm{L}_{0}>0.55$ when $\Delta \mathrm{T}_{\text {sub,in }}=4.5^{\circ} \mathrm{C}$ compared to that when $\Delta \mathrm{T}_{\text {sub,in }}=13.5^{\circ} \mathrm{C}$. This is due to the fact that the sliding bubbles often detached from the wall at this region and subsequently condensed when $\Delta \mathrm{T}_{\text {sub,in }}=4.5^{\circ} \mathrm{C}$, which was observed from the side view using HSC 2 (see Figure 1).

The middle (both left and right sides) of Figure 3 clearly shows that the sliding peak was reduced as $\mathrm{G}$ increased. In the same context, the parametric test results shown in Figure 5, which were all obtained at higher mass 
flux (G) conditions than those shown in Figure 3, barely show sliding peaks even if we can still see some bouncing peaks at $\mathrm{L} / \mathrm{L}_{0} \approx 0.41$. In general, the bubbles size near the nucleation site $\left(0.41<\mathrm{L} / \mathrm{L}_{0}<0.45\right)$ decreased as $\mathrm{G}$ increased as shown on middle left of Figures 3 and 5, which is easily expected. Interestingly, however, this is not always the case downstream in the test channel as shown on the middle right of Figure 3. This plot shows that as the bubbles passed $\mathrm{L} / \mathrm{L}_{0} \approx 0.48$, the bubbles size measured at $\mathrm{G}=280 \mathrm{~kg} / \mathrm{m}^{2} \mathrm{~s}$ became larger than that measured at $\mathrm{G}=140 \mathrm{~kg} / \mathrm{m}^{2} \mathrm{~s}$. This is because the bubbles measured at $\mathrm{G}=280 \mathrm{~kg} / \mathrm{m}^{2} \mathrm{~s}$ recovered the increasing trend of bubble size after the sliding peak earlier than those measured at $\mathrm{G}=140 \mathrm{~kg} / \mathrm{m}^{2} \mathrm{~s}$ (see also the left of Figure 4 in which the sliding bubbles' growth rate fluctuated more significantly over a longer path at $\mathrm{G}=140 \mathrm{~kg} / \mathrm{m}^{2} \mathrm{~s}$ ). That is, the difference in bubble growth characteristic upstream significantly affected the sliding bubble size downstream.

The bottom of Figures 3 and 5 presents the effect of $\mathrm{q}_{\mathrm{w}}$ on sliding bubbles growth at low and high $\mathrm{G}$ conditions, respectively. The sliding bubbles size is observed to increase as a whole by increasing $\mathrm{q}_{\mathrm{w}}$ as expected.
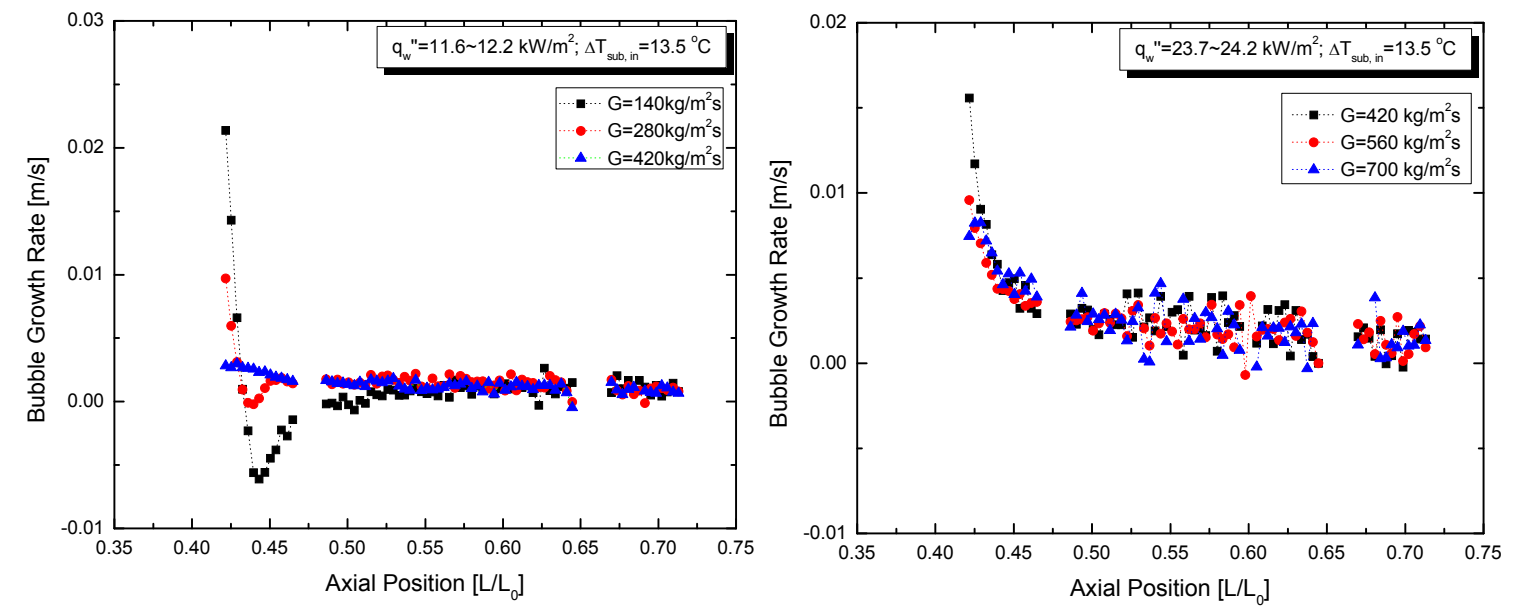

Figure 4. Effects of mass flux $(\mathrm{G})$ on sliding bubbles' growth rate ( $\partial \mathrm{D} / \partial \mathrm{t})$ along the flow path 

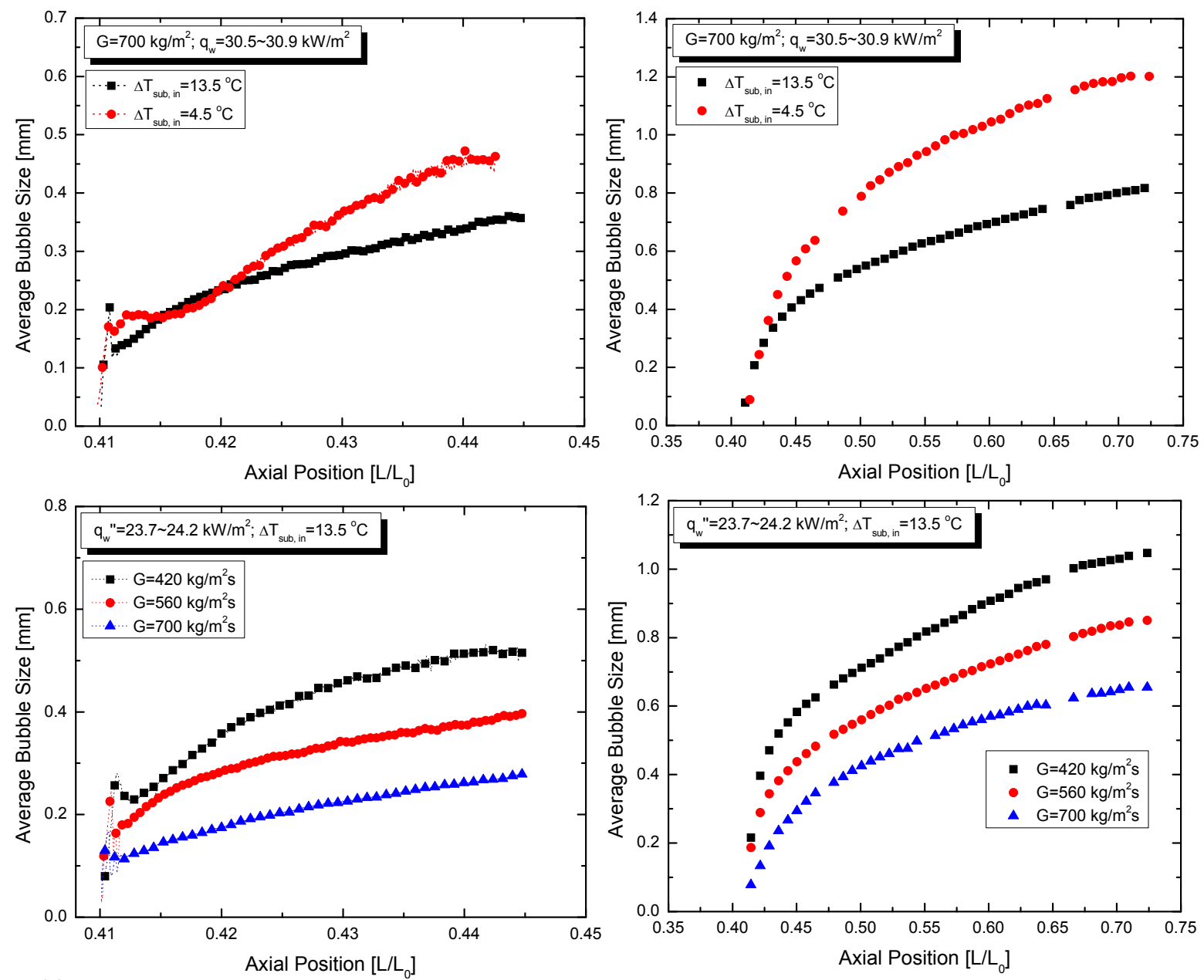

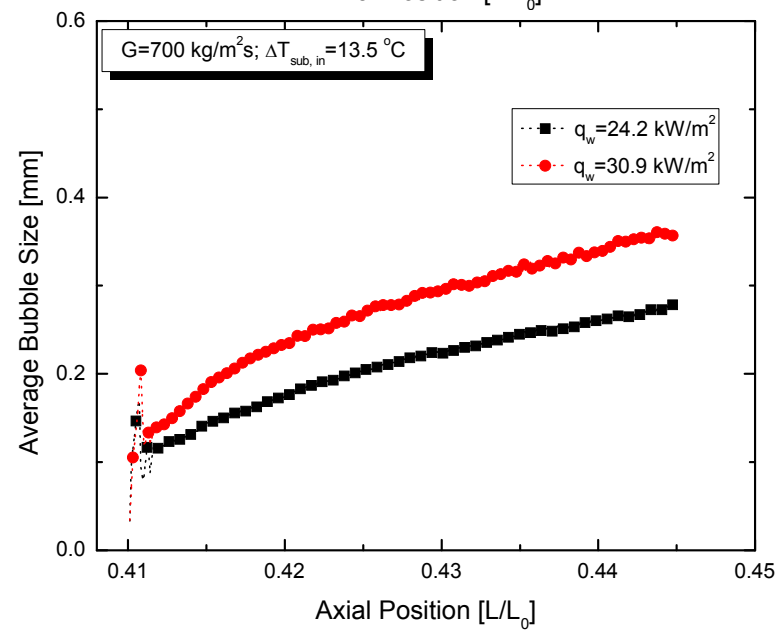

(Observed by HSC 1)

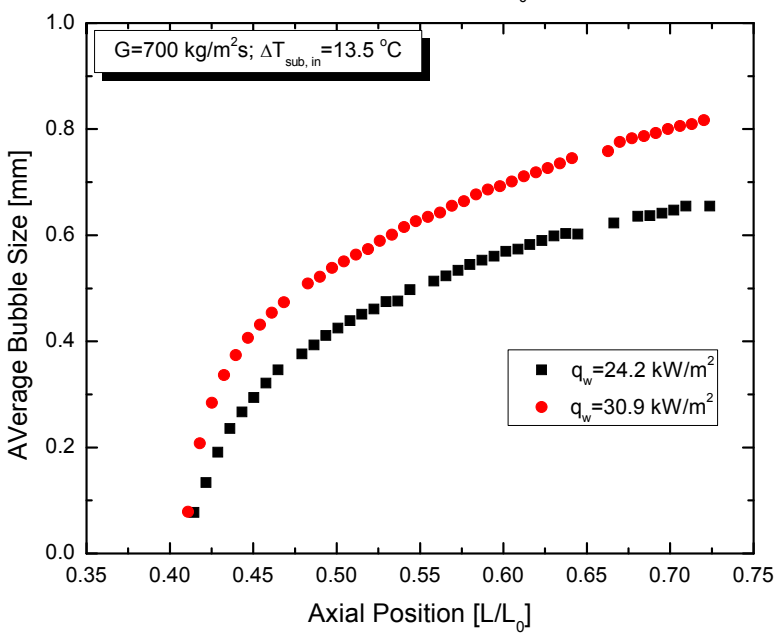

(Observed by HSC 3)

Figure 5. Effects of $\Delta \mathrm{T}_{\text {sub,in }}$ (top), $\mathrm{G}$ (middle), $\mathrm{q}_{\mathrm{w}}$ (bottom) on bubbles growth characteristics along the flow path at higher mass flux $(\mathrm{G})$ conditions (left column: observed by HSC 1, right column: observed by HSC 3 ) 


\subsection{Bubbles release frequency and subsequent coalescence while sliding}

\subsubsection{Bubbles release frequency}

The measurements of bubble frequency departing from nucleation site often show large discrepancy and inconsistencies among researchers (Euh et al., 2010; Situ et al., 2008), preventing us from achieving a correct understanding of the involved mechanisms. It is noted that we discussed several experimental issues behind this in our previous study (Yoo et al., 2014) and in Part 1 paper $^{\mathrm{A}}$. In this section, our measurements on bubble release frequency are presented with high statistical significance. Also, the experimental results are discussed in relation to other parameters measured simultaneously during the present work (e.g., bubble size, wall temperature).

In this study, vapor bubbles produced at the single nucleation site were generally in the interference bubble regime (Zuber, 1963) as discussed in section 3.1. That is, non-interactive and isolated bubbles were barely found at the nucleation site $\left(\mathrm{L}_{0} \approx \mathrm{L}_{0} \approx 0.41\right)$, therefore the departure frequency of isolated bubbles was hard to measure even with the high resolution camera HSC 1. Thus, instead of measuring the bubble departure frequency at the nucleation site, the frequency of isolated bubbles released from the nucleation site was investigated slightly downstream, i.e., $0.41<\mathrm{L} / \mathrm{L}_{0}<0.42$, and was defined as the bubble release frequency. In Table 2 , the average bubble release frequency measured is shown, for which more than 500 samples were typically collected at each test condition based on the measurement from HSC 1 (see Figure 1).

Figure 6 shows the effect of varying $\Delta \mathrm{T}_{\text {sub,in }}$ on the bubble release frequency at different $\mathrm{G}$ and $\mathrm{q}_{\mathrm{w}}$. A trend change is observed on the average bubble release frequency when increasing $\Delta \mathrm{T}_{\text {sub,in }}$; from a slightly

increasing trend for the low $\mathrm{G}$ and $\mathrm{q}_{\mathrm{w}}$ cases (i.e., $\mathrm{G}=140 \mathrm{~kg} / \mathrm{m}^{2} \mathrm{~s}, \mathrm{q}_{\mathrm{w}}=9.5 \sim 9.7 \mathrm{~kW} / \mathrm{m}^{2}$ ) towards a decreasing trend for the higher $\mathrm{G}$ and $\mathrm{q}_{\mathrm{w}}$ cases. The decreasing trend of bubble release frequency with $\Delta \mathrm{T}_{\text {sub,in }}$ implies that the wall heat transfer modes, especially quenching (Forster and Greif, 1959) were enhanced by increasing $\Delta \mathrm{T}_{\text {sub,in. }}$. This is due to the fact that at higher subcooling conditions, the amount of wall temperature drop during an ebullition cycle will increase because the lower temperature liquid repeatedly replenishes the wall as the bubbles leave space while departing (or releasing). Also, the average wall temperature, which was measured by the IR camera (not shown) was observed to be reduced by increasing $\Delta \mathrm{T}_{\text {sub,in }}$; and thus the recovery of wall superheat after the wall temperature drop due to quenching is expected to progress more slowly at higher subcooling condition. Therefore, we consider that both (i) the larger wall temperature drop caused by quenching and (ii) the slower recovery of wall superheat at higher $\Delta \mathrm{T}_{\text {sub,in }}$ led mainly to an increase in time intervals between successive boiling events, which is why the 
decreasing trend of bubble release frequency was observed as $\Delta \mathrm{T}_{\text {sub,in }}$ increased as shown in Figure 6 . On the other hand, the changes in bubble release frequency affected by $\Delta \mathrm{T}_{\text {sub,in }}$ were relatively insignificant and opposite when $\mathrm{G}$ was low, i.e., $\mathrm{G}=140 \mathrm{~kg} / \mathrm{m}^{2}$ (this will be further discussed with Figure 9 later in this section).

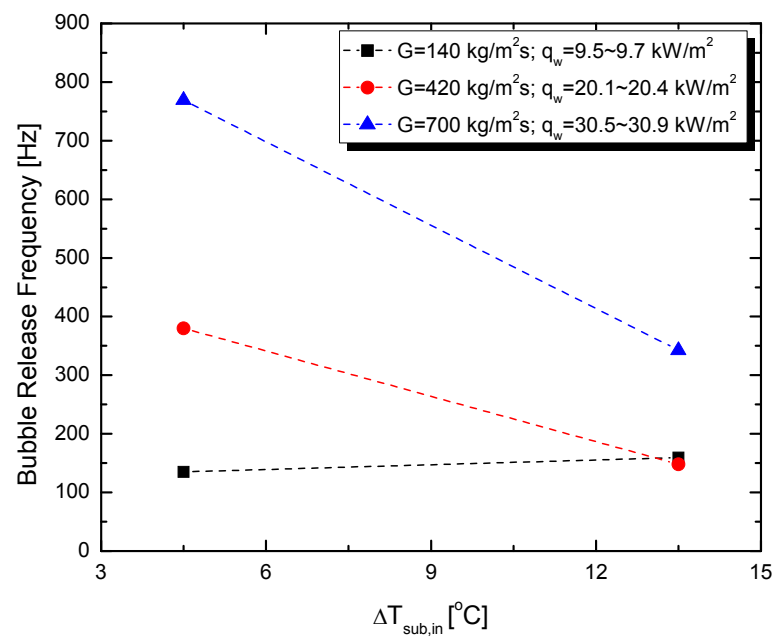

Figure 6. Effects of inlet subcooling $\left(\Delta \mathrm{T}_{\text {sub,in }}\right)$ on bubble release frequency

Figures 7 presents the measured bubble release frequency according to the changes in G, in which the bubble release frequencies measured at $\Delta \mathrm{T}_{\text {sub,in }}=4.6^{\circ} \mathrm{C}$ are shown on the left while those measured at $\Delta \mathrm{T}_{\text {sub,in }}=13.5^{\circ} \mathrm{C}$ are shown on the right. The bubble release frequency varied according to $\mathrm{G}$ in a quite different manner under the two $\Delta \mathrm{T}_{\text {sub,in }}$ conditions. Specifically, when $\Delta \mathrm{T}_{\text {sub,in }}=4.5^{\circ} \mathrm{C}$, the bubble release frequency increased proportionally according to $\mathrm{G}$ whereas such a consistent tendency was not found when $\Delta \mathrm{T}_{\text {sub,in }}=13.5^{\circ} \mathrm{C}$.

To explain this, we argue that there exist a competing process while increasing $\mathrm{G}$ between single-phase forced convection and bubble-induced heat transfer modes (e.g., evaporation and quenching), as illustrated in Figure 8. In section 3.1.2, the bubble size near the nucleation site was observed to decrease consistently as G increased (e.g., middle left of Figures 3 and 5), and the wall heat transfer due to evaporation of sliding bubbles ( $\mathrm{q}_{\mathrm{e}}$ ) was found to be reduced as well by increasing $\mathrm{G}$ (Yoo, 2015). Also, we can easily expect that the efficiency of quenching heat transfer $\left(\mathrm{q}_{\mathrm{Q}}\right)$ will decrease as $\mathrm{G}$ increases because the smaller bubbles will draw only a limited amount of surrounding liquid and thus cause a limited wall temperature drop as they depart (or release) from the nucleation site. As a result, the time to recover the wall superheat after the wall temperature drop may become shorter. Therefore, we can deduce, as illustrated in Figure 8, the deteriorated bubble-induced heat transfer modes $\left(\mathrm{q}_{\mathrm{e}}, \mathrm{q}_{\mathrm{Q}}\right)$ while 
increasing $\mathrm{G}$ led to a proportional relation of bubble release frequency to $\mathrm{G}$ as shown on the left of Figure 7 . It is also noted that, the interfacial drag acting on bubbles can be another reason causing such increasing trend of bubble release frequency as $\mathrm{G}$ increases (the interfacial drag around bubbles will be discussed further in section 3.3).
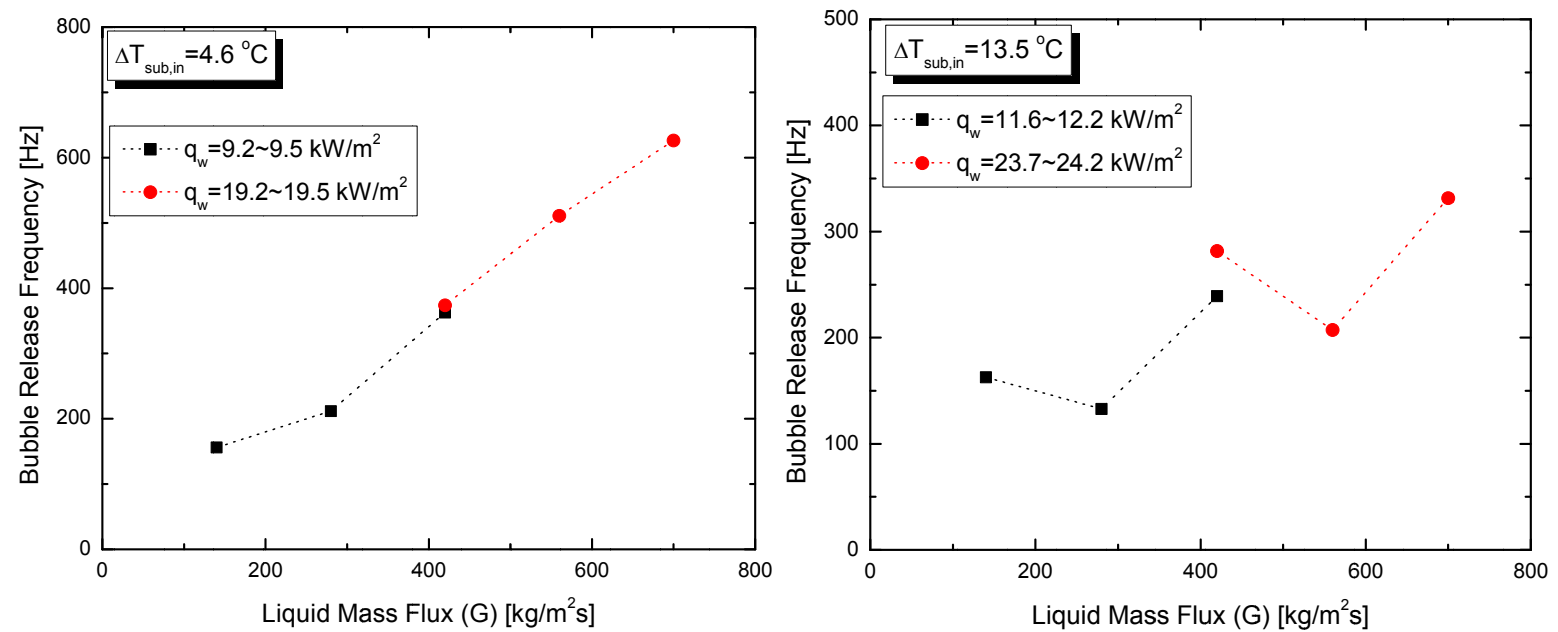

Figure 7. Effects of mass flux (G) on bubble release frequency at $\Delta \mathrm{T}_{\text {sub,in }}=4.6^{\circ} \mathrm{C}$ (left) and $\Delta \mathrm{T}_{\text {sub,in }}=13.5^{\circ} \mathrm{C}$ (right)

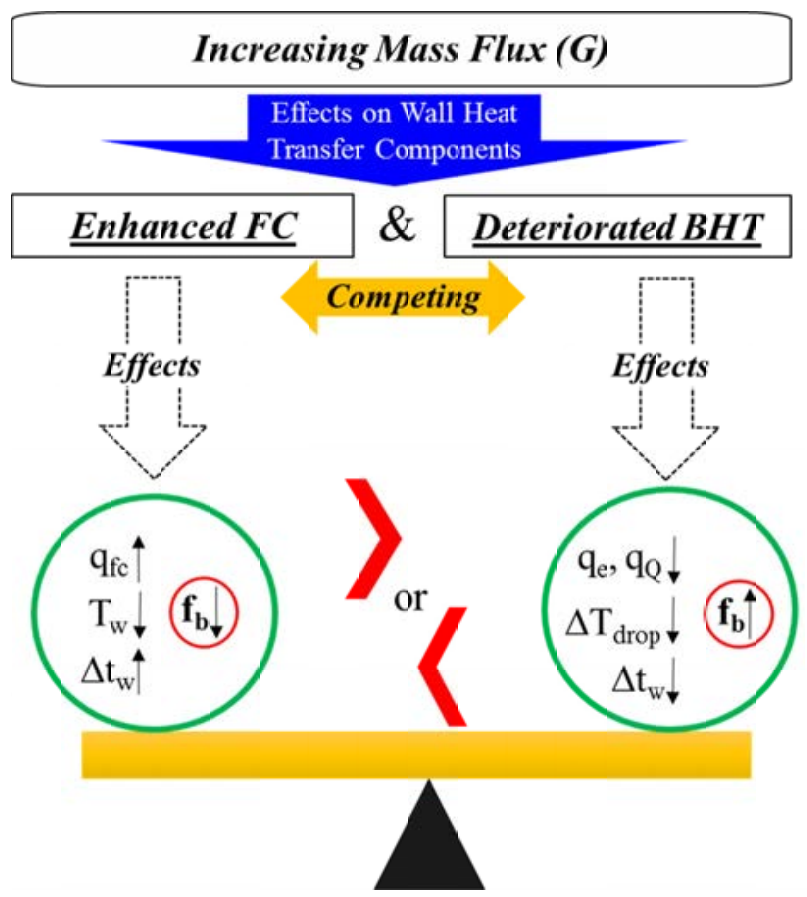

FC: forced convection (single-phase) BHT: bubble-induced heat transfer $\mathrm{f}_{\mathrm{b}}$ : bubble release frequency $\Delta \mathrm{T}_{\text {drop }}$ : wall temperature drop due to $\mathrm{q}_{\mathrm{e}}$ or $\mathrm{q}_{\mathrm{o}}$ $\Delta \mathrm{t}_{\mathrm{w}}$ : waiting time between boiling events $\mathrm{T}_{\mathrm{w}}$ : time-averaged wall temperature

Figure 8. A competing process between the wall heat transfer components while increasing mass flux $(\mathrm{G})$ 
On the other hand, the right side of Figure 7 shows that the bubble release frequency decreased initially as $\mathrm{G}$ increased, but the frequency increased again as $\mathrm{G}$ increased more, the trend of which was commonly observed for the tests conducted at different values of $\mathrm{q}_{\mathrm{w}}$ and G. Obviously, the cooling performance due to flowing liquid (i.e., single-phase forced convection) is enhanced as $\mathrm{G}$ increases. In contrast, the relative significance of bubble-induced heat transfer modes will deteriorate by increasing $\mathrm{G}$ as previously discussed (the direct evidence of this is provided in section 4). As shown in Figure 8, the enhanced forced convection will extend the time necessary to recover the wall superheat $\left(\Delta \mathrm{t}_{\mathrm{w}}\right)$, leading to a decrease in bubble release frequency by increasing G. Meanwhile, the diminishing role of bubble-induced heat transfer modes may cause an increase in bubble release frequency as $\mathrm{G}$ increases. This implies that the dependency of bubble release frequency on $\mathrm{G}$ is probably determined whether the wall temperature variation is dominated by the enhancing forced convection or by the deteriorating bubble-induced heat transfer modes. This competing process can explain why the bubble release frequency shown on the right of Figure 7 varies inconsistently as $\mathrm{G}$ increases. Also, it is interesting to say that whenever such a reciprocal relation existed between $\mathrm{G}$ and bubble release frequency the bubble size measured around the nucleation site decreased less when increasing the same amount of $\mathrm{G}$, implying relatively less deterioration of bubble-induced heat transfer modes. This observation further supports the argument discussed above.

Figure 9 shows how sensibly bubble release frequency was affected by the changes in test conditions like Ja depending on G. It is noted that the Jacob numbers (Ja) shown in Figure 9 were estimated based on the average wall temperature measured at the elevation of nucleation site. The results shown reveal that the bubble release frequency varied insignificantly at low $\mathrm{G}$ (i.e., $\mathrm{G}=140 \mathrm{~kg} / \mathrm{m}^{2} \mathrm{~s}$ or $\mathrm{Re} \approx 3125$ ) despite the significant changes in Ja, whereas the variation range significantly increased at higher $\mathrm{G}$ (or Re).

In Figure 10, we also evaluate the performance of existing models to predict bubble departure frequency based on the present data. The models tested include: (i) Cole (1960)'s model, (ii) Ivey (1967)'s model, (iii) Zuber (1959)'s model, (iv) Basu et al. (2005)'s model, and (v) Situ et al. (2008)'s model. For low $\operatorname{Re}(\operatorname{Re} \approx 3125$ or $\mathrm{G}=140 \mathrm{~kg} / \mathrm{m}^{2} \mathrm{~s}$ ), Cole (1960)'s model showed the best performance, showing less than $5 \%$ deviation from the data taken at both high and low subcooling conditions; but the prediction capability significantly deteriorated as Re increased. For higher $\operatorname{Re}(\operatorname{Re}>3125)$, Situ et al. (2008)'s model tended to predict the present data better than the other models. However, when comparing the prediction capability depending on Ja as shown on the right of Figure 10, Basu et al. (2005)'s model showed the best performance at Ja $>34$ while both Ivey (1967)'s model and Situ et al. 
(2008)'s model predicted the present data comparably well at $\mathrm{Ja}<34$. Based on these observations, the best performance region of the existing models depending on flow conditions can be defined as shown in Figure 11 ( $\varepsilon$ denotes the absolute mean deviation from the present data).

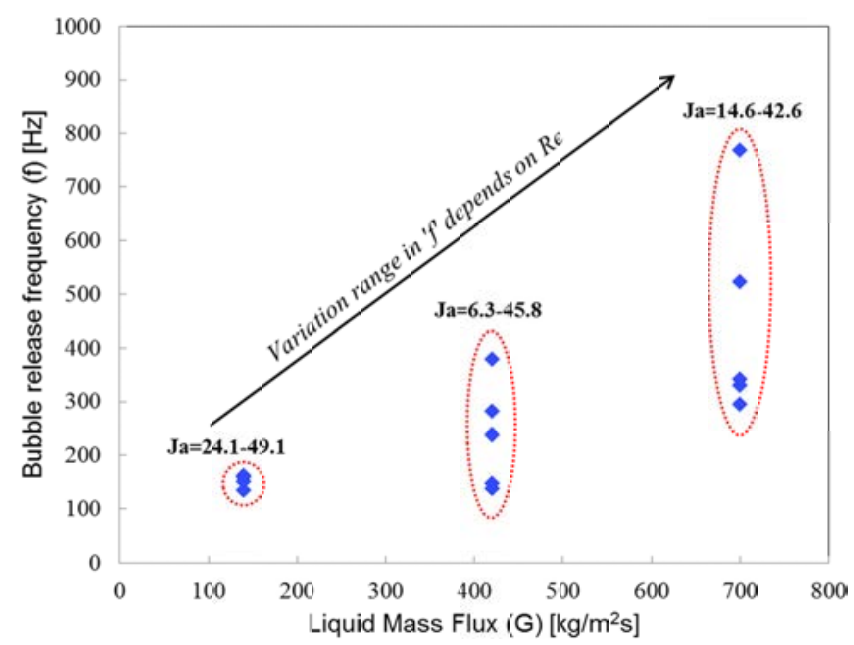

Figure 9. Variation range of bubble release frequency depending on Re
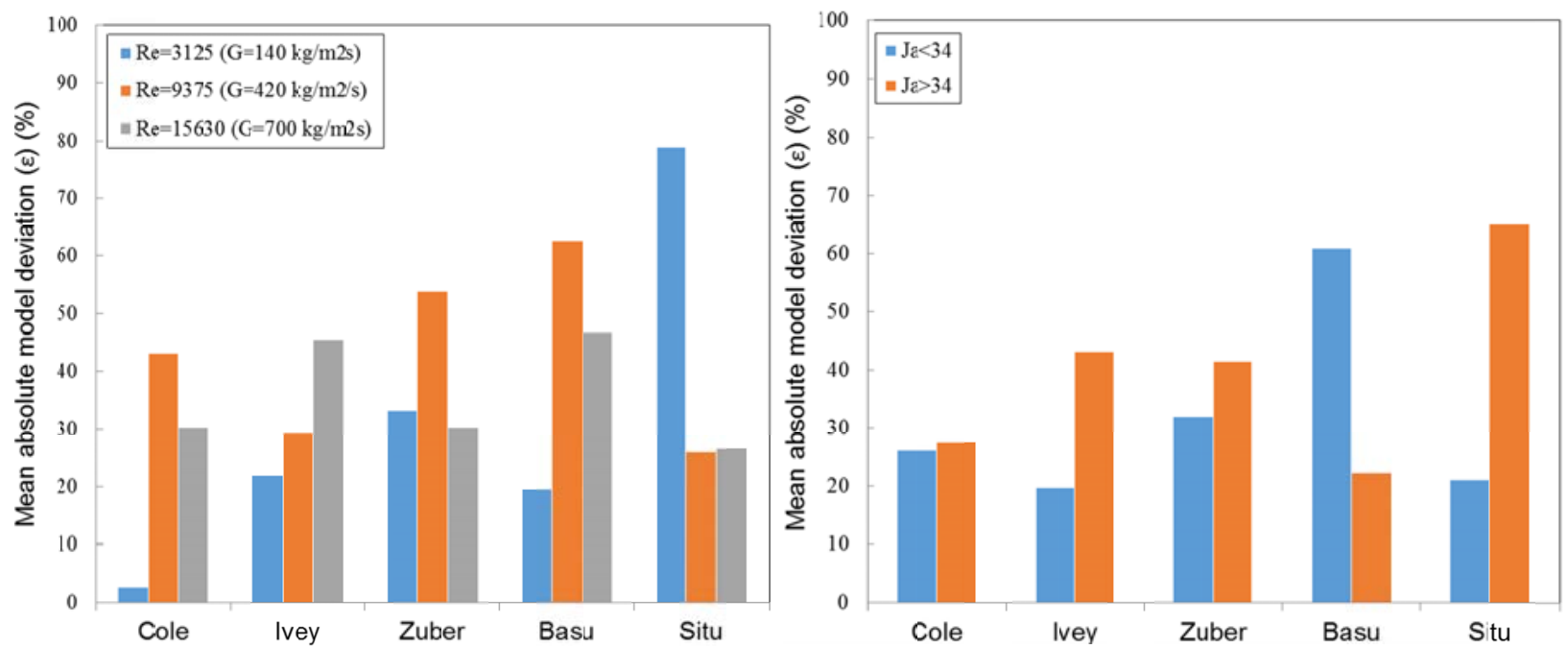

Figure 10. Prediction capability of bubble departure frequency models depending on Re (left) and Ja (right) 


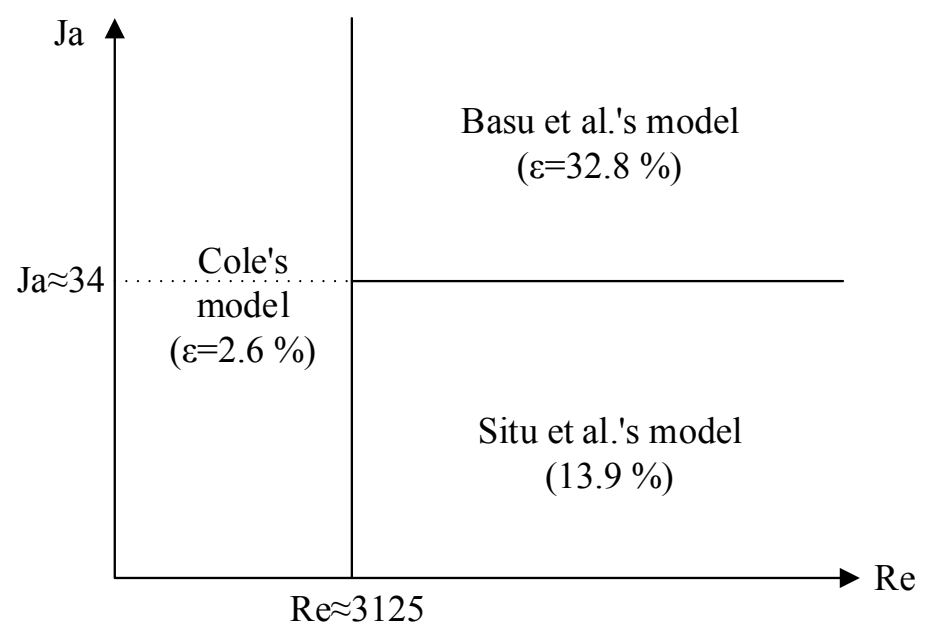

Figure 11. Best performance region of bubble departure frequency models depending on flow conditions

\subsubsection{Bubbles coalescence while sliding}

One of the major findings in this study is that the number of sliding bubbles decreased significantly along the flow path after the bubbles left the nucleation site. Also, it was found that such a decrease in bubble number mostly resulted from the coalescence of sliding bubbles, rather than collapse of vapor bubbles due to condensation (bubbles' break-up were also negligible). To the best of our knowledge, the coalescence of sliding bubbles which originated from the "single" nucleation site was barely addressed by other researchers. A few discussion available in literature is about the coalescence of sliding bubbles originating from "separate" nucleation sites (Basu et al., 2005; Prodanovic et al., 2002), the insight of which has been applied to recent boiling models for CFD application (Bae et al., 2010; Yeoh et al., 2008). Accordingly, we discuss in this section such a rather unknown phenomenon, the coalescence of sliding bubbles originating from the single nucleation site. For this study, the variation of bubble number along the flow path, which was attributed to the bubbles coalescence while sliding, was analyzed based primarily on the measurement from HSC 3 (see Figure 1). Note that, since HSC 3 has limitations in capturing detailed bubbles motion near the nucleation site due to the limited resolutions as well as the measurement view (Yoo et al., 2014), we used the experimental results obtained from the high-resolution camera HSC 1 as well to compensate for these limitations, the details of which are described below.

\subsubsection{Analysis procedure}


The specific procedures to analyze the bubble number along the flow path are as follows: The total number of bubbles released from the single nucleation site $\mathrm{N}_{0}$ during the measurement time of HSC $3(80 \mathrm{~s})$ was first estimated based on average bubble release frequency measured by HSC 1 . That is, $\mathrm{N}_{0}$ was obtained by multiplying the average bubble release frequency by the total measurement time of HSC 3 . The sliding bubbles number at axial locations $0.41<\mathrm{L} / \mathrm{L}_{0}<0.45$ was estimated in the similar way. Meanwhile, the number of bubbles passing through the axial locations at $\mathrm{L} / \mathrm{L}_{0}>0.45$ was obtained by analyzing the sliding bubbles' trajectory observed by HSC 3; the bubbles' trajectory during the measurement time of HSC 3 was analyzed using ImageJ plugin software MTrack2 (Stuurman, 2003). Then, the bubbles number captured along the flow path was presented by N/ $\mathrm{N}_{0}$; $\mathrm{N}$ denotes the number of bubbles passing through a specific axial location $\left(\mathrm{L} / \mathrm{L}_{0}\right)$ during the measurement time of HSC 3. Note that $\mathrm{N} / \mathrm{N}_{0}$ is always 1 at the axial location of single nucleation site, i.e., $\mathrm{L} / \mathrm{L}_{0} \approx 0.41$.

\subsubsection{Observation on sliding bubbles coalescence}

On the left and right sides of Figure 12, the variation of bubble number captured along the flow path is compared for the test cases of two different $\Delta \mathrm{T}_{\text {sub,in }}$ while $\mathrm{G}$ and $\mathrm{q}_{\mathrm{w}}$ were held constant. The left side of Figure 12 shows that $\mathrm{N} / \mathrm{N}_{0}$ decreased more sharply along the flow path when inlet subcooling was higher $\left(\Delta \mathrm{T}_{\text {sub,in }}=13.5^{\circ} \mathrm{C}\right)$. Since the number of bubbles barely decreased due to the collapse of bubbles during these tests, the result implies that the sliding bubbles coalesced more by increasing $\Delta \mathrm{T}_{\text {sub,in }}$. Also, we observed that, due to the decrease in $\Delta \mathrm{T}_{\text {sub,in }}$, the bubbles released from the nucleation site spread more in the lateral direction as they slid along the flow path. This naturally caused the bubbles to have less chances of collision at lower $\Delta \mathrm{T}_{\text {sub,in }}$ because the bubbles were distributed over a larger area while travelling.

However, similar comparison made at the higher $\mathrm{G}$ and $\mathrm{q}_{\mathrm{w}}$ shown on the right of Figure 12 show a quite different result against those shown on the left. Specifically, the decrease in $\mathrm{N} / \mathrm{N}_{0}$ along the flow path became sharper in the case with lower $\Delta \mathrm{T}_{\text {sub,in }}\left(=4.5^{\circ} \mathrm{C}\right)$, especially near the nucleation site at $0.41<\mathrm{L} / \mathrm{L}_{0}<0.5$ while the decreasing slopes became comparable at further downstream region $\mathrm{L} / \mathrm{L}_{0}>0.5$. We also found that the decreasing slope of bubble number near the nucleation site was closely related to bubbles release frequency. That is, the sliding bubbles were more likely to merge with each other near the nucleation site at the test conditions involving higher bubble release frequency (note that $\mathrm{N}_{0}$ shown in Figures 12-14 is proportional to bubble release frequency according to the definition described in section 3.2.2.1). 

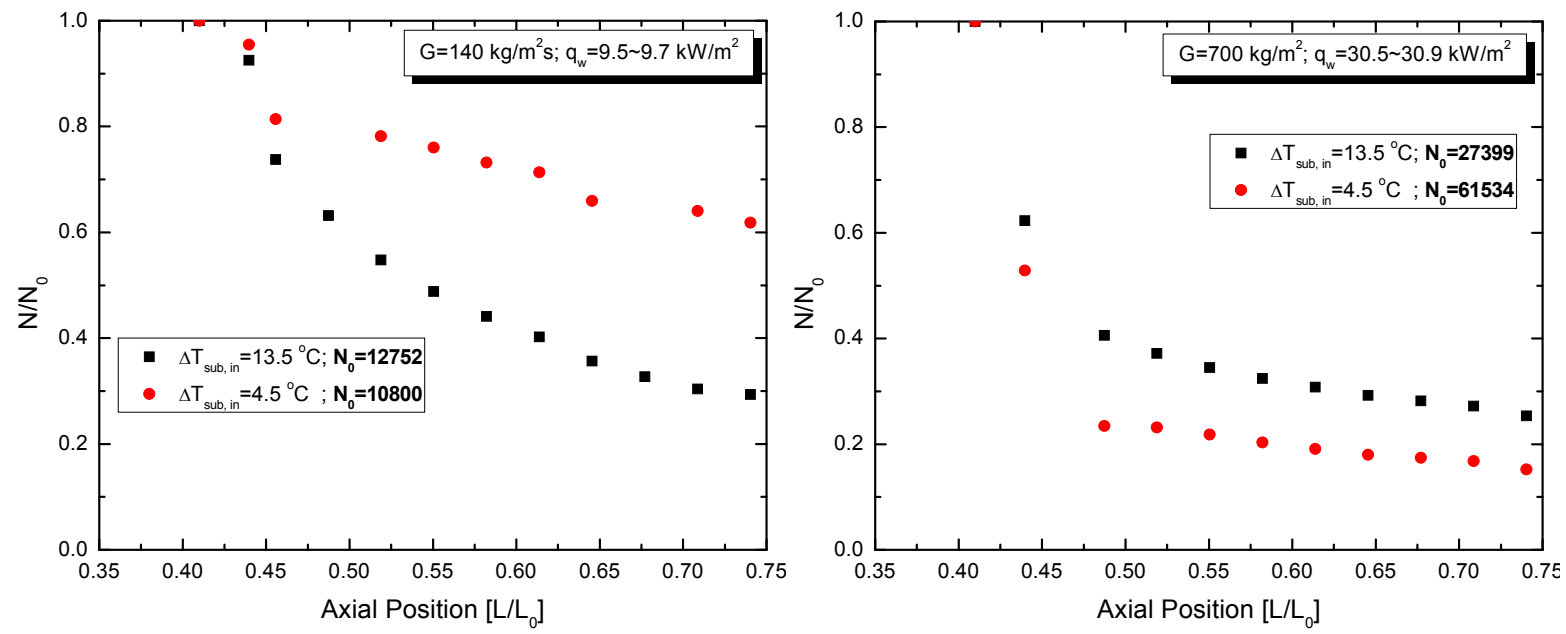

Figure 12. Effects of inlet subcooling $\left(\Delta \mathrm{T}_{\text {sub,in }}\right)$ on bubble number variation along the flow path

In Figure 13, the parametric effects of $G$ on the variation of sliding bubble number along the flow path are shown. On the left of Figure 13, N/N $\mathrm{N}_{0}$ decreased quite sharply near the nucleation site when $\mathrm{G}=420 \mathrm{~kg} / \mathrm{m}^{2} \mathrm{~s}$ compared to the other cases of lower $\mathrm{G}$ (i.e., 140 and $280 \mathrm{~kg} / \mathrm{m}^{2} \mathrm{~s}$ ). However, when $\mathrm{G}=420 \mathrm{~kg} / \mathrm{m}^{2} \mathrm{~s}$, the number of sliding bubbles barely changed at $\mathrm{L} / \mathrm{L}_{0}>0.55$ meaning that the coalescence of sliding bubbles was negligible; whereas, for the other cases $\left(\mathrm{G}=140\right.$ and $\left.280 \mathrm{~kg} / \mathrm{m}^{2} \mathrm{~s}\right), \mathrm{N} / \mathrm{N}_{0}$ kept decreasing as the bubbles moved downstream. Also, similar to the previous observation in Figure 12, $\mathrm{N} / \mathrm{N}_{0}$ tended to decrease more sharply (i.e., bubbles coalesced more readily) near the nucleation site as bubble release frequency (or $\mathrm{N}_{0}$ ) increased. But, the decreasing trend significantly slowed down downstream in the test channel when such sharp decrease in $\mathrm{N} / \mathrm{N}_{0}$ existed upstream. A similar trend can also be found on the right of Figure 13. Figure 14 shows the parametric effect of $\mathrm{q}_{\mathrm{w}}$ on sliding bubbles coalescence behavior, in which the dependency on $\mathrm{q}_{\mathrm{w}}$ looks insignificant. 

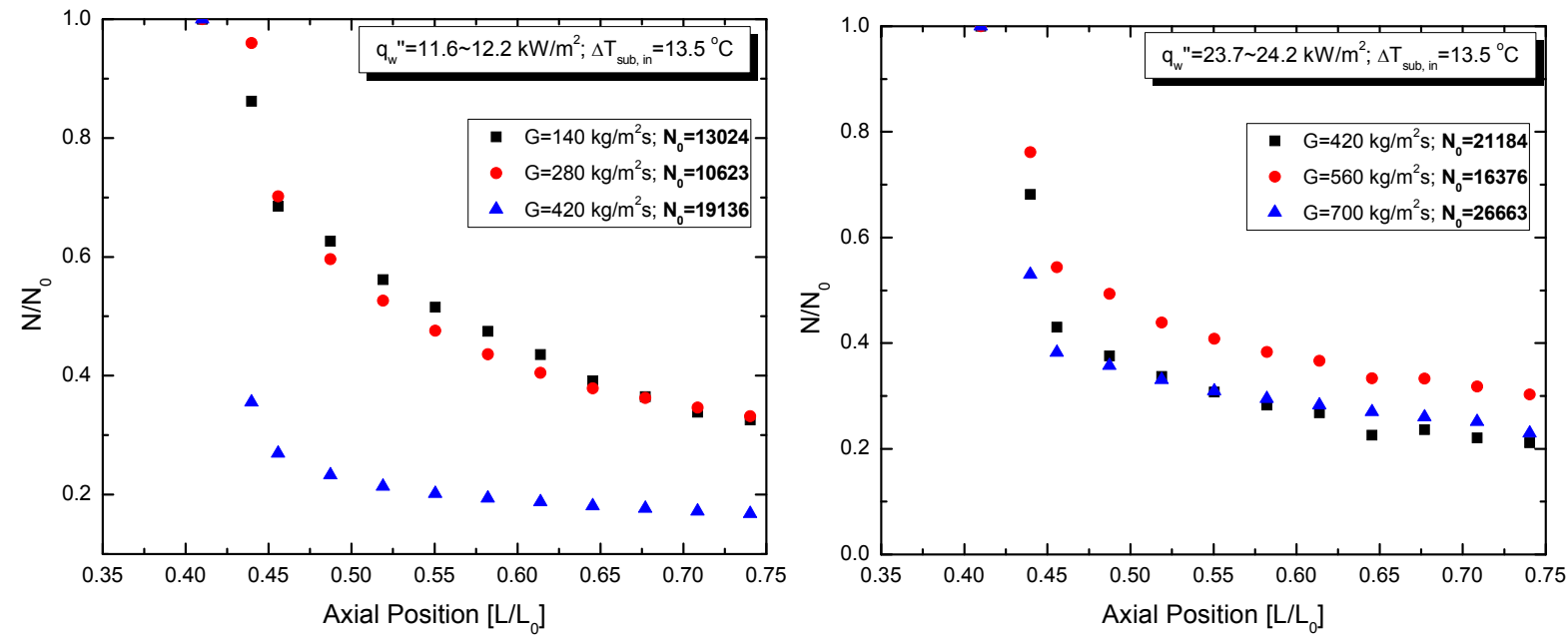

Figure 13. Effects of mass flux $(\mathrm{G})$ on bubble number variation along the flow path
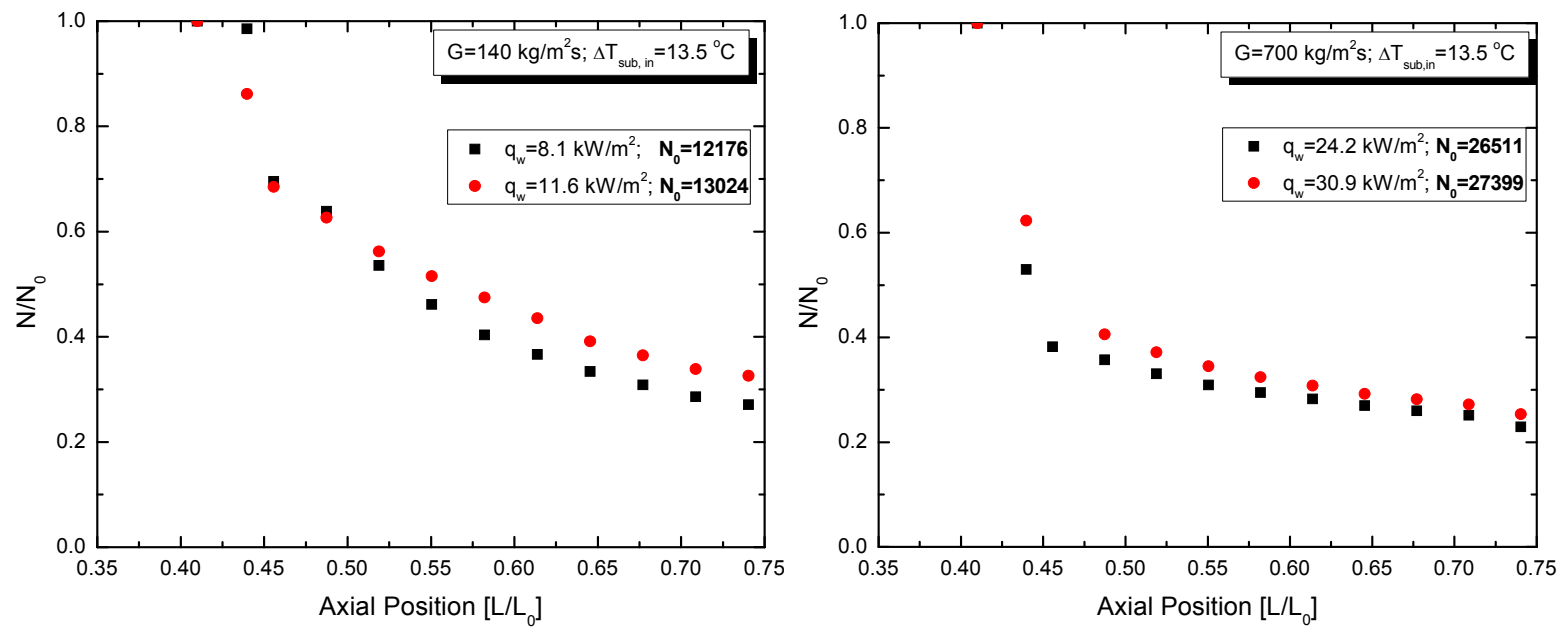

Figure 14. Effects of wall heat flux $\left(\mathrm{q}_{\mathrm{w}}\right)$ on bubble number variation along the flow path

\subsection{Sliding bubbles velocity subsequent to departure}

Until recently, the sliding bubble velocity, the characteristic behavior in subcooled boiling flow, has little been informed despite its importance in wall heat transfer and two-phase modeling (Ramstorfer et al., 2005; Situ et al., 2005). In this section, the characteristics of sliding bubble velocity are investigated based on both micro- and macroscopic observations of sliding bubbles (section 3.3.1). Also, the relative velocity of sliding bubbles against the local flowing liquid is discussed (section 3.3.2). 


\subsubsection{Experimental observation}

In Figures 15 and 16, the axial sliding bubble velocity is presented, in which the experimental results obtained by HSC 1 (microscopic view near the nucleation site) is shown on the left while the results obtained by HSC 3 (macroscopic view) are shown on the right. The $\mathrm{u}_{\text {in }}$ shown in Figures 15 and 16 (blue dash-dot line) denotes the bulk liquid velocity applied to the test section inlet.

On the top two figures in Figure 15, the effect of $\Delta \mathrm{T}_{\text {sub,in }}$ on sliding bubble velocity is shown. It is noted that all the experimental cases in Figure 15 correspond to those shown in Figure 3 presenting the sliding bubbles growth behavior. The sliding bubble velocity at $\Delta \mathrm{T}_{\text {sub,in }}=4.5^{\circ} \mathrm{C}$ increased faster initially compared to that at $\Delta \mathrm{T}_{\text {sub,in }}=13.5^{\circ} \mathrm{C}$. Also, in both cases of $\Delta \mathrm{T}_{\text {sub,in }}$, the sliding bubble velocity decreased after reaching the maximum at $\mathrm{L} / \mathrm{L}_{0} \approx 0.44 \sim 0.46$. This is similar to the increase and subsequent decrease in sliding bubble size (i.e., sliding peak) shown in Figure 3 (top right). Subsequently, the sliding bubble velocity at $\Delta \mathrm{T}_{\text {sub,in }}=13.5^{\circ} \mathrm{C}$ continued to slowly increase whereas the bubble velocity at $\Delta \mathrm{T}_{\text {sub,in }}=4.5^{\circ} \mathrm{C}$ decreased slightly after $\mathrm{L} / \mathrm{L}_{0} \approx 0.55$ (Figure 15 top right). However, the bouncing peak of bubble size (see Figure 3-top left) barely affected the sliding bubble velocity as shown in Figure 15 (top left).

In the middle of Figure 15, sliding bubble velocities influenced by $\mathrm{G}$ are compared. It can be seen that the sliding bubble velocity decreased as $\mathrm{G}$ increased at the region $\mathrm{L} / \mathrm{L}_{0}<0.53$. This is similar with the trend of sliding bubbles' growth observed under the same test conditions at the similar region, shown on the middle of Figure 3. Further downstream in the test channel, i.e., $\mathrm{L} / \mathrm{L}_{0}>0.53$, Figure 15 (middle right) also shows that the sliding bubble velocity at $\mathrm{G}=280 \mathrm{~kg} / \mathrm{m}^{2} \mathrm{~s}$ became higher than that at $\mathrm{G}=140 \mathrm{~kg} / \mathrm{m}^{2} \mathrm{~s}$; a similar trend can also be found in the bubble growth behavior shown in Figure 3 (middle right). This suggests a close relationship between sliding bubble growth and velocity. However, in Figure 15 (middle right), the sliding bubble velocity at $\mathrm{G}=420 \mathrm{~kg} / \mathrm{m}^{2} \mathrm{~s}$ became the highest as the bubbles moved downstream $\mathrm{L} / \mathrm{L}_{0}>0.53$ despite the smallest bubble size over the whole flow path as shown in Figure 3 (middle right). This is because a certain force other than buoyancy, which is considered interfacial drag, significantly affected the sliding bubble velocity at this downstream region $\left(\mathrm{L} / \mathrm{L}_{0}>0.53\right)$. It is noted that during this work the increasing $\mathrm{G}$ consistently caused the decrease in sliding bubble velocity near the single nucleation site whereas the trend became reversed as the bubbles slid downstream. This implies that the effect of increasing $\mathrm{G}$ on sliding bubble velocity varied depending on the distance from the nucleation site. Specifically, the decrease in buoyancy by increasing G lowered the sliding bubbles' velocity near the nucleation site, whereas the interfacial drag 
led to the increase in sliding bubble velocity downstream as G increased (note that the sliding bubbles' upward motion was resisted by liquid at low $\mathrm{G}\left(\right.$ i.e., $\mathrm{u}_{\mathrm{r}}=\mathrm{u}_{\mathrm{l}}-\mathrm{u}_{\mathrm{b}}<0$ ) while the effect became reversed as $\mathrm{G}$ increased (i.e., $\mathrm{u}_{\mathrm{r}}>0$ ), which will be discussed in detail in section 3.3.2).

The bottom of Figure 15 presents the effect of $\mathrm{q}_{\mathrm{w}}$ on sliding bubble velocity, showing that a higher $\mathrm{q}_{\mathrm{w}}$ led to a higher sliding bubble velocity along the flow path. This is because the buoyancy force and the local liquid velocity averaged over the bubble height increased as the bubble size increased by increasing $\mathrm{q}_{\mathrm{w}}$ (see Figure 3 bottom).

In Figure 16, the similar parametric test results performed at higher $\mathrm{G}$ conditions than those shown in Figure 15 are presented. The effect of $\Delta \mathrm{T}_{\text {sub,in }}$ (Figure 16 top), $\mathrm{G}$ (Figure 16 middle), and $\mathrm{q}_{\mathrm{w}}$ (Figure 16 bottom) on sliding bubble velocity was observed similar as shown in Figure 15, except for the fact that the sliding bubble velocity was often significantly lower than $u_{i n}$. 

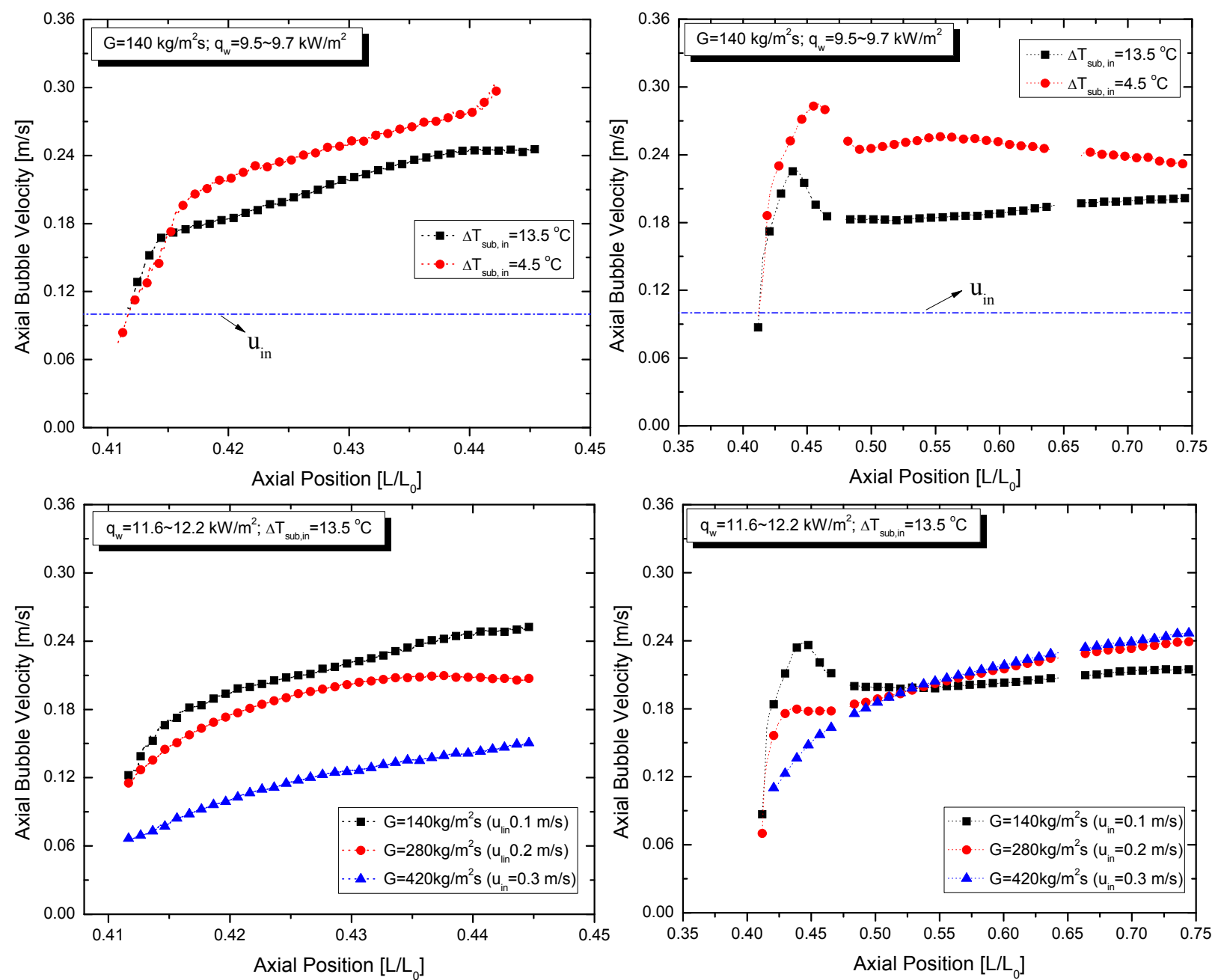

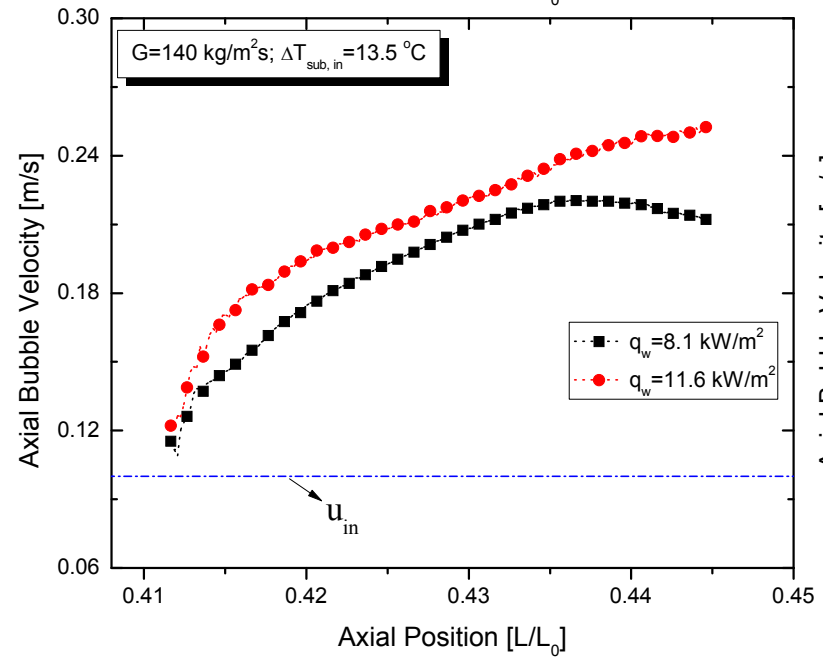

(Observed by HSC 1)

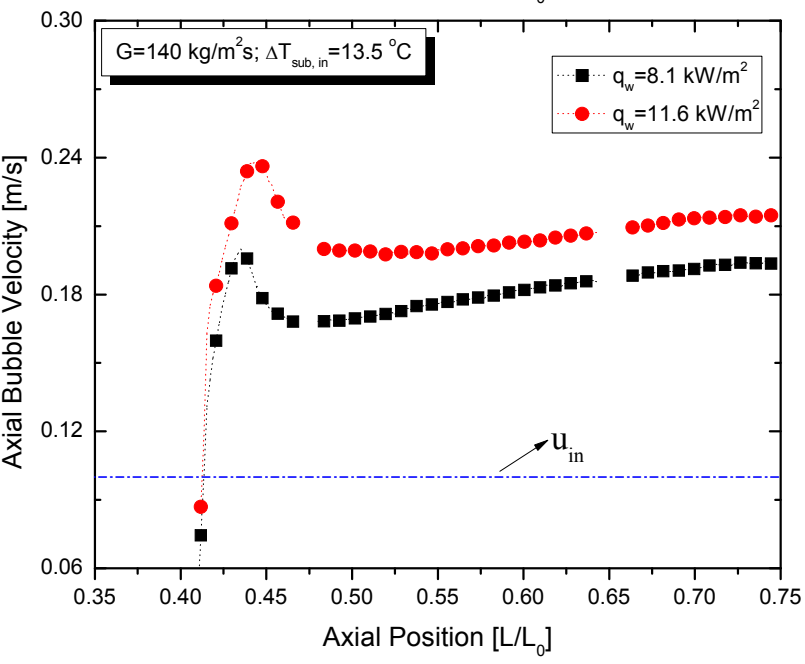

(Observed by HSC 3)

Figure 15. Effects of $\Delta \mathrm{T}_{\text {sub,in }}$ (top), $\mathrm{G}$ (middle), $\mathrm{q}_{\mathrm{w}}$ (bottom) on sliding bubble velocity along the flow path (left column: observed by HSC 1, right column: observed by HSC 3) 

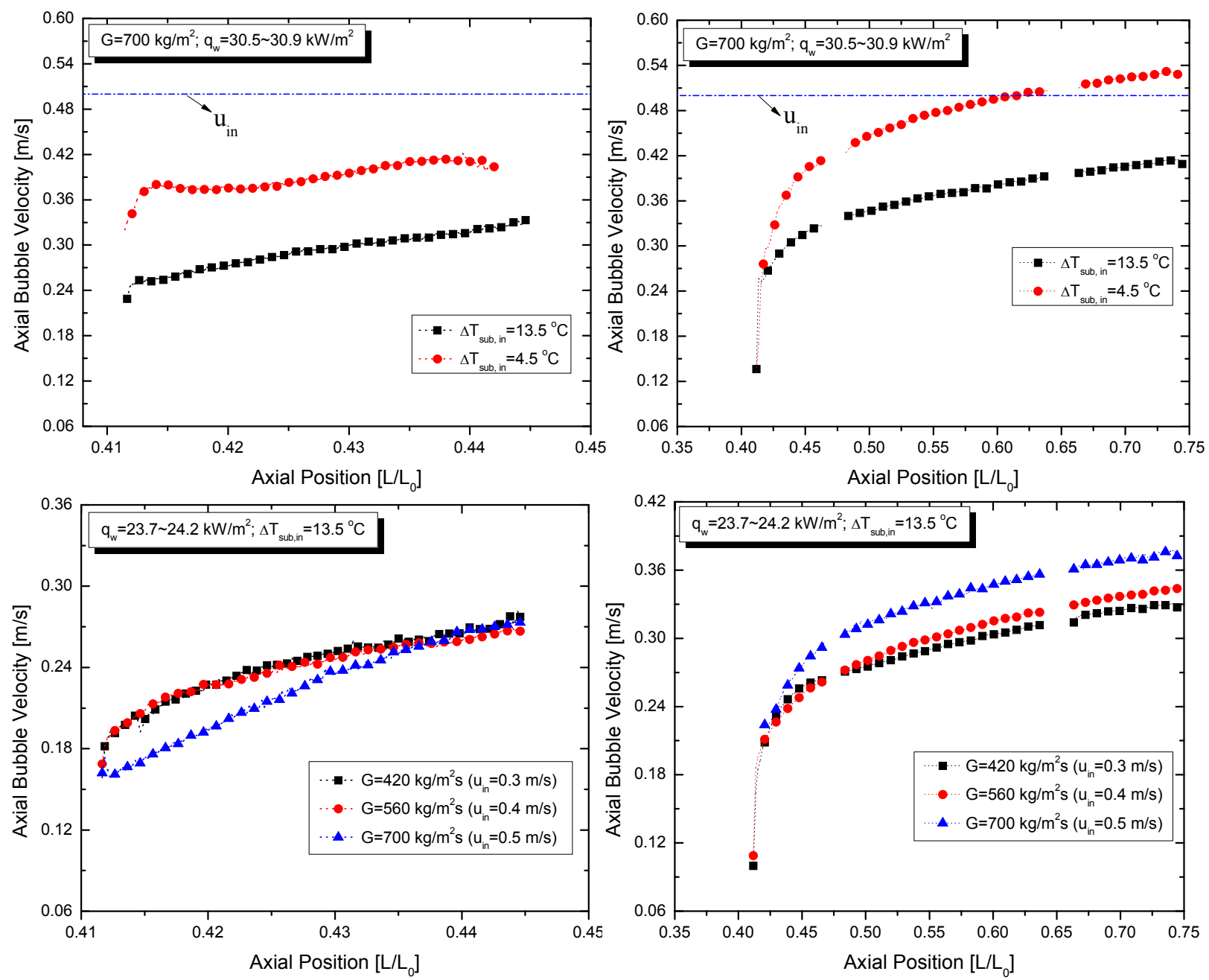

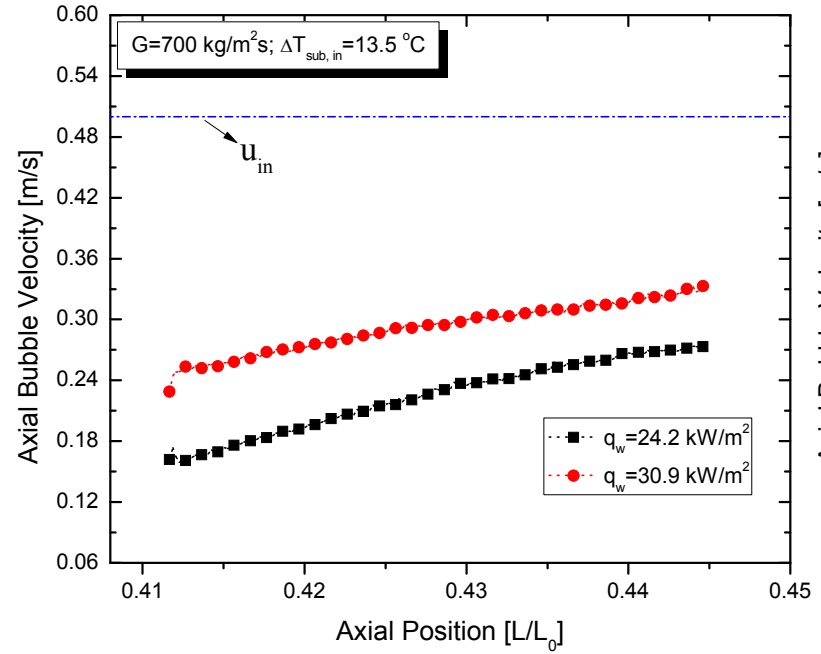

(Observed by HSC 1)

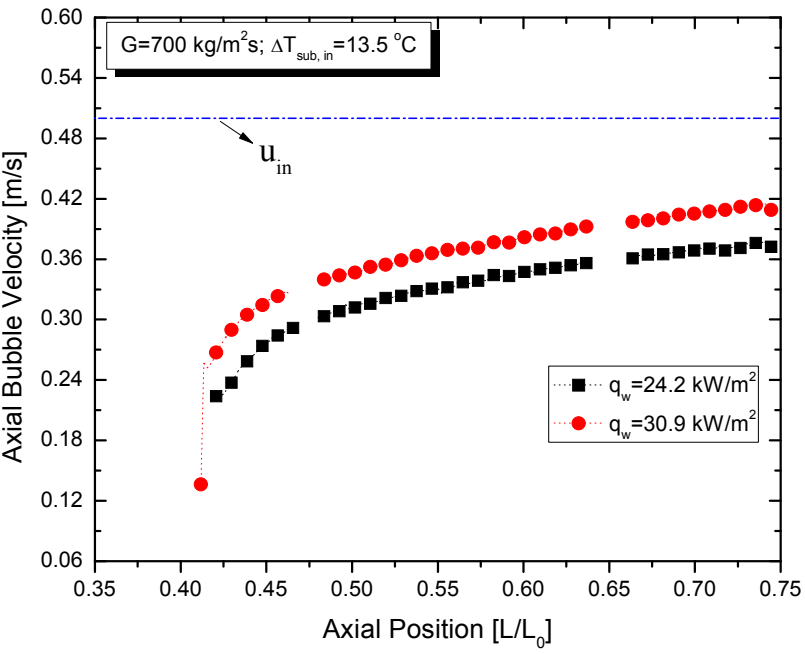

(Observed by HSC 3)

Figure 16. Effects of $\Delta \mathrm{T}_{\text {sub,in }}$ (top), $\mathrm{G}$ (middle), $\mathrm{q}_{\mathrm{w}}$ (bottom) on sliding bubble velocity along the flow path at higher G conditions (left column: observed by HSC 1, right column: observed by HSC 3) 
It is noted that, as pointed out by Situ et al. (2005), no experimental correlation exists so far in literature for sliding bubble velocity. Consequently, even in the recent CFD works for subcooled boiling flow, overly simplified assumptions are often employed (e.g., $u_{b}=u_{l}$ or $\left.u_{b}=0.5 u_{l}\right)$ (Bae et al., 2010; Yun et al., 2012). Meanwhile, Basu et al. (2005) used a fitting curve derived based on the data produced by Maity (2000) to account for the increase in sliding bubble velocity with time; and the same curve was also adopted by Yeoh et al. (2008). However, it was found, as shown in Figure 17, this curve predicted the present data reasonably only at low G (Figure 17 left) while its performance significantly deteriorated as $\mathrm{G}$ increased (Figure 17 right). This proves that the curve, formulated as a function of bulk liquid velocity and bubble sliding time (Basu et al., 2005), is too simple to properly reflect the physics determining the sliding bubble velocity. Therefore, further work is obviously needed to improve the existing approaches evaluating sliding bubble velocity.
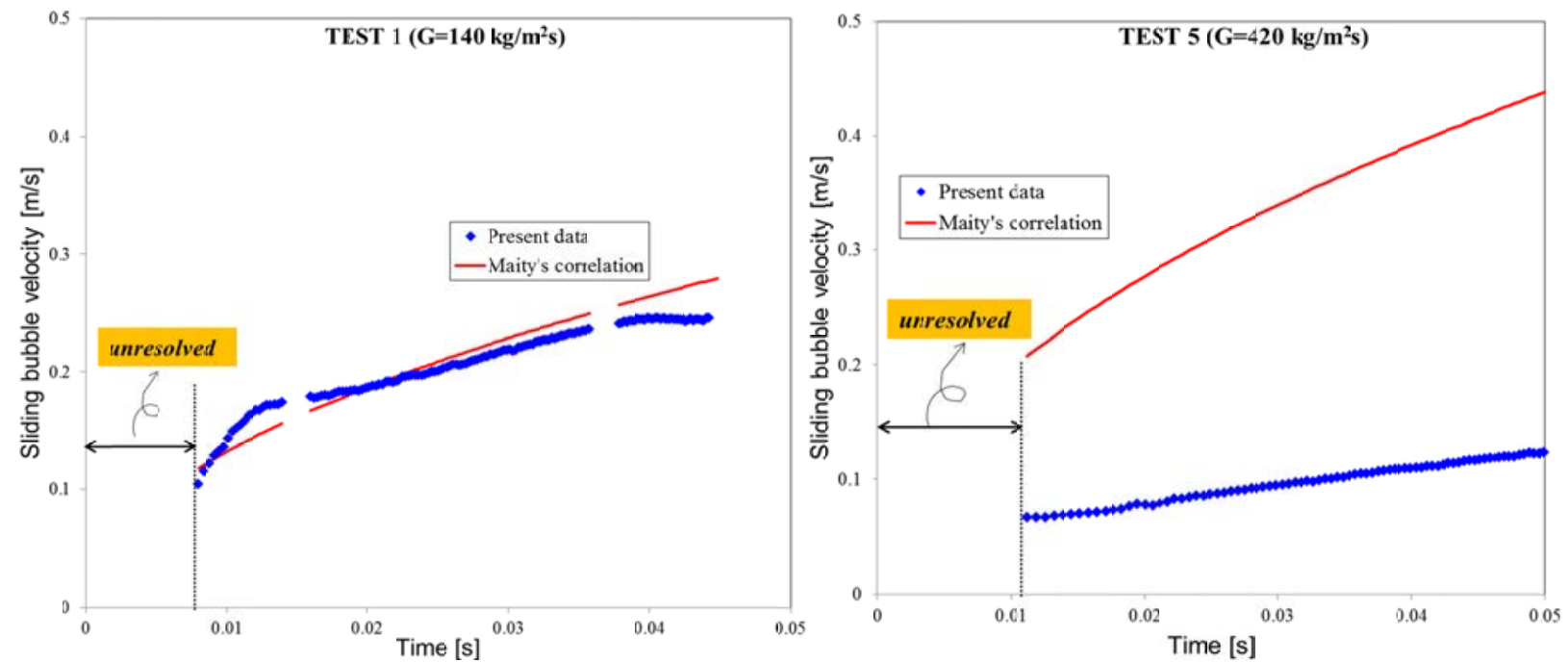

Figure 17. Performance of the predictive curve based on Maity's data (2000) against the present data ( "unresolved" region occurred due to the vigorous interaction among bubbles near the nucleation site) 


\subsubsection{Discussion on relative velocity of sliding bubbles against local flowing liquid}

The relative velocity of sliding bubbles against local flowing liquid is an important factor to evaluate interfacial forces (e.g., interfacial drag force, shear-lift force) (Ishii and Zuber, 1979; Klausner et al., 1993) and nearwall turbulence (Ramstorfer et al., 2005; Sato et al., 1981), etc. Nevertheless, it is still barely informed especially in flow boiling system and we discuss this matter in this section.

Since the local liquid velocity around bubbles was not measured in this study, we evaluated the near-wall liquid velocity using the universal velocity profile for single-phase turbulent flow as Situ et al. (2005) in which Troniewski and Ulbrich (1984)'s results were employed to estimate the friction factor of the present channel. The relative velocity of sliding bubble is defined as follows:

$$
u_{r} \equiv u_{l}-u_{b}
$$

where $u_{r}$ is the relative velocity of sliding bubble, $u_{1}$ is the local liquid velocity at the center of sliding bubble, and $u_{b}$ is the sliding bubble velocity.

Eq. (2) implies that the sliding bubbles' upward motion is aided by liquid when $\mathrm{u}_{\mathrm{r}}>0$, whereas it is resisted when $\mathrm{u}_{\mathrm{r}}<0$. In Figure 18, $\mathrm{u}_{\mathrm{r}}$ is compared (presented as open symbols) for all the experimental cases shown in Figures 15 and 16 on the left and right columns, respectively. Also, the sliding bubble size $\left(D_{b}\right)$ is shown together (presented as solid symbols) to investigate how the relative bubble velocity varied in relation to the sliding bubble size.

At low $\mathrm{G}$, shown on the left of Figure 18, $\mathrm{u}_{\mathrm{r}}$ was mostly negative along the flow path, i.e., $\mathrm{u}_{\mathrm{b}}>\mathrm{u}_{1}$. On the other hand, the results shown on the right column (parametric tests performed at higher $\mathrm{G}$ ) show that $\mathrm{u}_{\mathrm{r}}$ was often positive, i.e., $\mathrm{u}_{\mathrm{b}}<\mathrm{u}_{1}$. Also, in cases of low $\mathrm{G}$ (Figure 18 left), $\mathrm{u}_{\mathrm{r}}$ decreased initially near the nucleation site and subsequently increased until reaching the constant value downstream, while the varying trend was quite different at higher $\mathrm{G}$ (Figure 18 right). This is because at low $\mathrm{G}$ the variation of $\mathrm{u}_{\mathrm{r}}$ was dominated by the sharp increase in $\mathrm{u}_{\mathrm{b}}$ near the nucleation site. As discussed in section 3.3.1, at low $\mathrm{G} \mathrm{u}_{\mathrm{b}}$ sharply increased near the nucleation site as the bubbles grew fast whereas $\mathrm{u}_{1}$ increased only gently according to the bubble growth (note that liquid velocity gradient normal to the wall is gentle at low Re). In contrast, at higher $\mathrm{G}$ the $\mathrm{u}_{\mathrm{r}}$ near the nucleation site was determined dominantly by $\mathrm{u}_{1}$ because $\mathrm{u}_{1}$ increased sharply as the bubbles grew within the velocity boundary layer whereas both the bubble growth and the increase in $\mathrm{u}_{\mathrm{b}}$ was relatively restricted as discussed in section 3.3.1.

The top right of Figure 18 also shows that $\mathrm{u}_{\mathrm{r}}$ decreased continuously downstream instead of reaching a constant value. This is because $\mathrm{u}_{\mathrm{b}}$ increased consistently at the downstream region (see Figure 16 top right) whereas 
$\mathrm{u}_{1}$ varied insignificantly as the sliding bubbles went out of the velocity boundary layer while growing though this region.

We discussed in section 3.3.1, in the middle and right side of Figures 15 and 16, that the influence of G on the sliding bubble velocity looked different depending on the distance from the nucleation site. This is because a certain force other than buoyancy, i.e., interfacial drag $\left(\mathrm{F}_{\mathrm{d}}\right)$ significantly affected the sliding bubble velocity downstream. In the middle section of Figure 18 (both left and right sides), $\mathrm{u}_{\mathrm{r}}$ became larger by increasing G, ending up with positive values of $\mathrm{u}_{\mathrm{r}}$ at the highest $\mathrm{G}$ shown on both sides. This implies that $\mathrm{F}_{\mathrm{d}}$ aided the bubbles' upward motion at the highest $G\left(u_{r}>0\right)$ while the bubbles' motion was resisted by $F_{d}$ at lower $G\left(u_{r}<0\right)$. Thus, we can deduce that, although the sliding bubble velocity decreased near the nucleation site as $G$ increased due to the decreasing buoyancy force (see the middle of Figures 15 and 16), the $\mathrm{F}_{\mathrm{d}}$ played a key role in reversing that trend as the bubbles slid away from the nucleation site (note that we assumed here the buoyancy and interfacial drag are the main forces determining the sliding bubble velocity). 

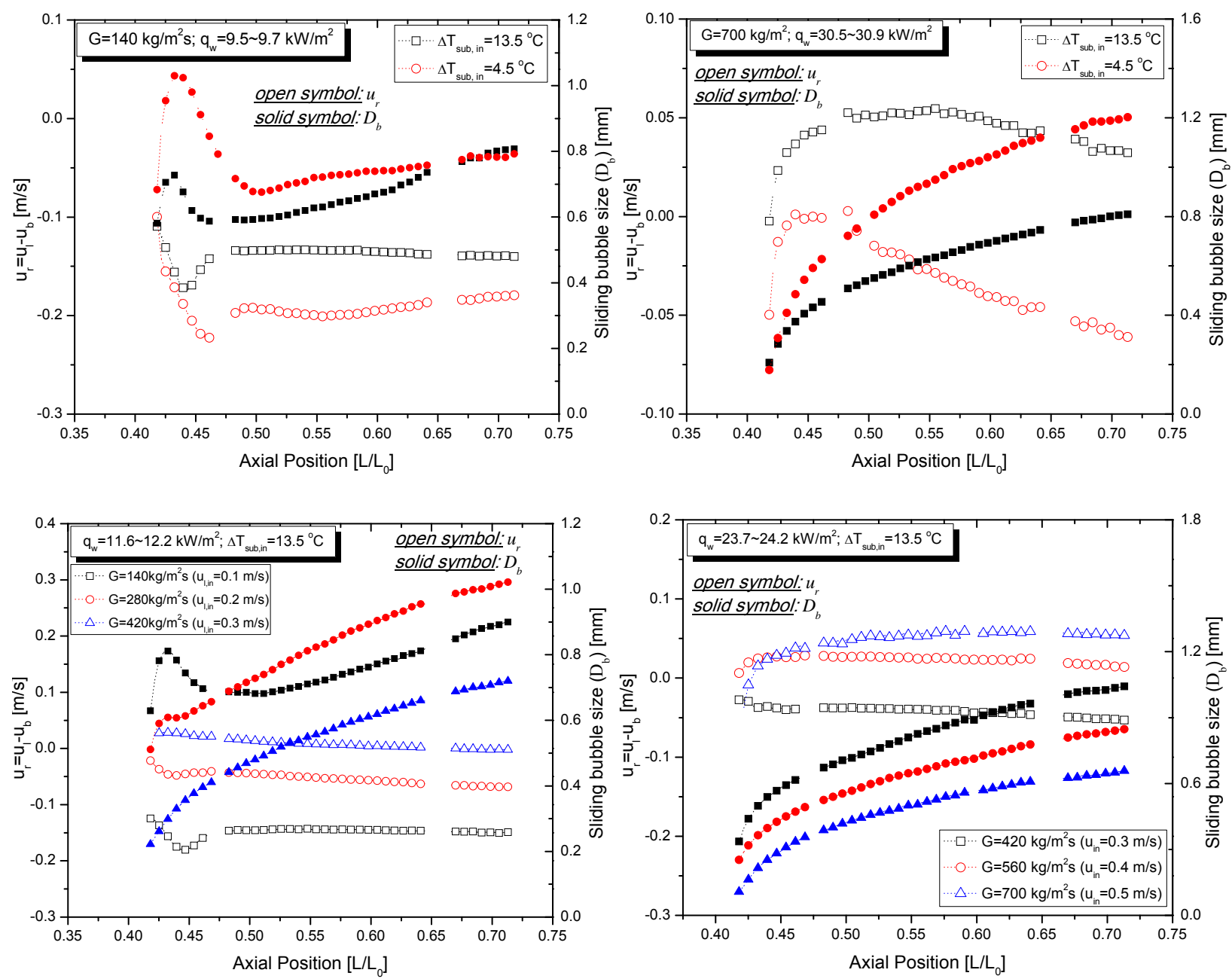

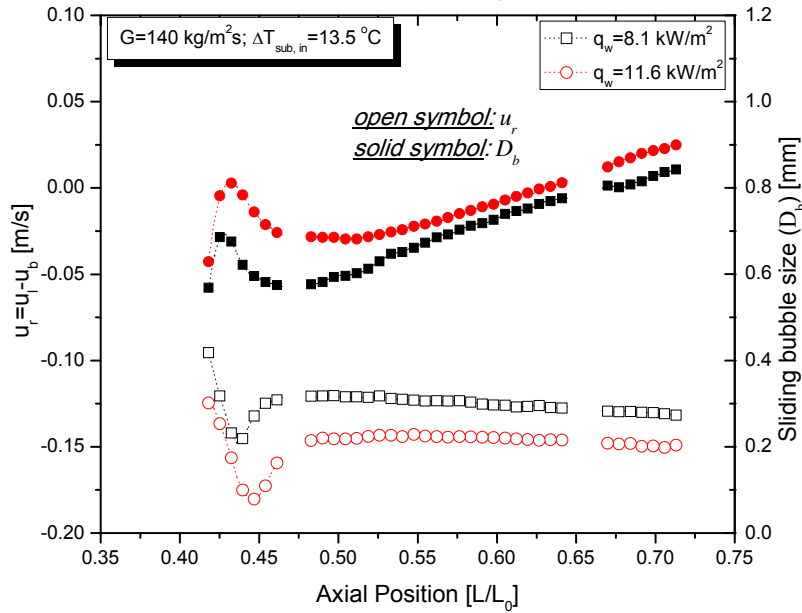

(At lower G conditions)

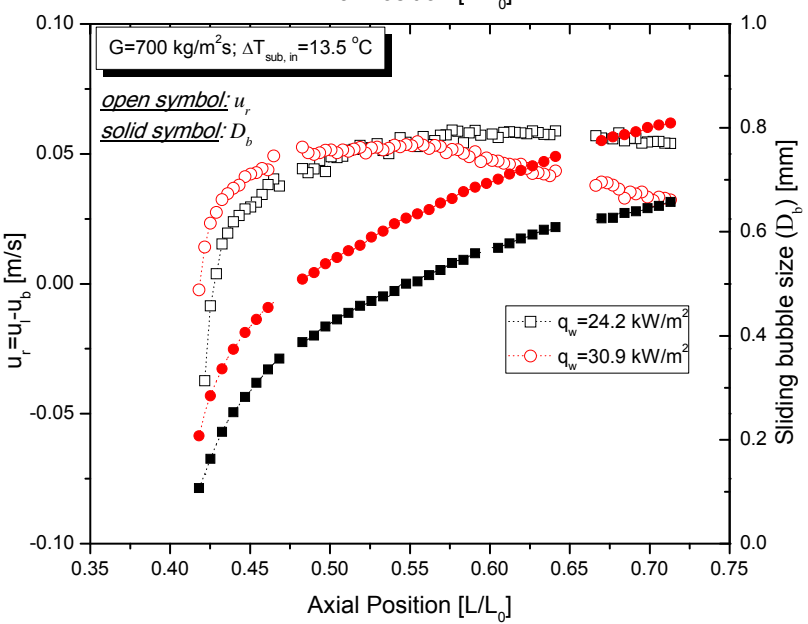

(At higher $\mathbf{G}$ conditions)

Figure 18. Relative velocity of sliding bubbles $\left(\mathrm{u}_{\mathrm{r}}\right.$ ) affected by $\Delta \mathrm{T}_{\text {sub,in }}$ (top), $\mathrm{G}$ (middle), $\mathrm{q}_{\mathrm{w}}$ (bottom) 
3.4. Bubble size distribution and its development while sliding

The stochastic nature of boiling parameters such as bubble departure diameter in forced convective boiling has been reported in literature (Klausner et al., 1993; Thorncroft et al., 1998). Recently, the importance of addressing the stochastic feature has been increasingly emphasized both for improved modeling and reliable measurement (Martinez-Cuenca et al., 2015; Yoo et al., 2014). In this section, the statistical distribution of sliding bubble size, which has barely been informed so far, is discussed based on the analyses of numerous data ensuring reliable statistics $^{\mathrm{A}}$. In particular, the axial development of bubble size distribution through sliding is of major interest.

For the present study, probability density functions (PDFs) were established at two different axial locations in the test channel: One was relatively close to the nucleation site at $\mathrm{L}_{\mathrm{L}} \approx 0.43$, and the other was farther downstream of the nucleation site at $\mathrm{L} / \mathrm{L}_{0} \approx 0.71$. Typically, more than 13,000 and 5,000 data samples were used to construct the PDFs at $\mathrm{L} / \mathrm{L}_{0} \approx 0.43$ and $\mathrm{L} / \mathrm{L}_{0} \approx 0.71$, respectively at each test condition. The PDFs created in this way are shown in Figures 19-21, in which the bubble size distribution at different axial locations (i.e., L/ $\mathrm{L}_{0} \approx 0.43,0.71$ ) were presented by bar graphs in different colors. Also, since the PDFs were mostly well-fitted to Gaussian distribution, the fitted curves were shown in Figures 19-21 as well along with the bar graphs. The mean (m) and standard deviation $(\sigma)$ of the bubble size shown within these figures were obtained from the fitted Gaussian curves.

The effects of $\Delta \mathrm{T}_{\text {sub,in }}$ on the PDFs for bubble size can be found by comparing the sub-figures embedded in the left and right columns of Figure 19. The test cases shown in the left column $\left(\Delta \mathrm{T}_{\text {sub,in }}=13.5^{\circ} \mathrm{C}\right)$ show that the mean bubble size $(\mathrm{m})$ increased as the bubbles moved downstream from $\mathrm{L} / \mathrm{L}_{0} \approx 0.43$ to 0.71 while the standard deviation $\sigma$ barely changed. On the other hand, for the cases shown in the right column $\left(\Delta \mathrm{T}_{\text {sub,in }}=4.5^{\circ} \mathrm{C}\right), \sigma$ decreased as the bubbles moved from $\mathrm{L} / \mathrm{L}_{0} \approx 0.43$ to 0.71 . Comparing the sub-figures in the left and right columns of Figure 19 , the $\sigma$ at $\mathrm{L} / \mathrm{L}_{0} \approx 0.43$ became larger by decreasing $\Delta \mathrm{T}_{\text {sub,in }}$ while the increase was relatively insignificant downstream $\left(\mathrm{L} / \mathrm{L}_{0} \approx 0.71\right)$. Additionally, the PDFs in Figure 19 mostly followed Gaussian distribution quite well, except for the test case shown on the top right of Figure 19 at $\mathrm{L} / \mathrm{L}_{0} \approx 0.71$; it was observed in this test case that the sliding bubbles were more likely to detach from the wall (i.e., lift-off) downstream of the channel, which resulted in the frequent occurrence of smaller bubbles at $\mathrm{L} / \mathrm{L}_{0} \approx 0.71$.

In Figure 20, the effects of G on the PDFs for bubble size are presented on the left and right column, respectively. Figure 20 shows that by increasing $\mathrm{G}$ the $\sigma$ decreased slightly at both axial locations $\mathrm{L} / \mathrm{L}_{0} \approx 0.43$ and 
$\mathrm{L} / \mathrm{L}_{0} \approx 0.71$. However, the variation of $\sigma$ between $\mathrm{L} / \mathrm{L}_{0} \approx 0.43$ and $\mathrm{L} / \mathrm{L}_{0} \approx 0.71$ at each test case was only insignificant compared to that of mean bubble size $\mathrm{m}$.

In Figure 21, the effects of $\mathrm{q}_{\mathrm{w}}$ on the PDFs for bubble size are presented. The test cases of lower $\mathrm{q}_{\mathrm{w}}$ are in the left column, while those of higher $\mathrm{q}_{\mathrm{w}}$ are placed in the right column. It can be seen that by increasing $\mathrm{q}_{\mathrm{w}}$ both the $\mathrm{m}$ and $\sigma$ increased at both upstream $\left(\mathrm{L} / \mathrm{L}_{0} \approx 0.43\right)$ and downstream $\left(\mathrm{L} / \mathrm{L}_{0} \approx 0.71\right)$ locations, but the variation of $\sigma$ was relatively small. Also, for all of the cases shown in Figure 21, $\sigma$ was found to vary much less along the flow path compared to $\mathrm{m}$.

All observations discussed above indicate that the test conditions causing an increase in wall temperature (by decreasing $\Delta \mathrm{T}_{\text {sub,in }} / \mathrm{G}$ or by increasing $\left.\mathrm{q}_{\mathrm{w}}\right)$ tended to increase the $\sigma$ of bubble size both upstream $\left(\mathrm{L} / \mathrm{L}_{0} \approx 0.43\right)$ and downstream $\left(\mathrm{L} / \mathrm{L}_{0} \approx 0.71\right)$ in the test channel. However, the variation of $\sigma$ while sliding was always much smaller than that of mean bubble size (m). 

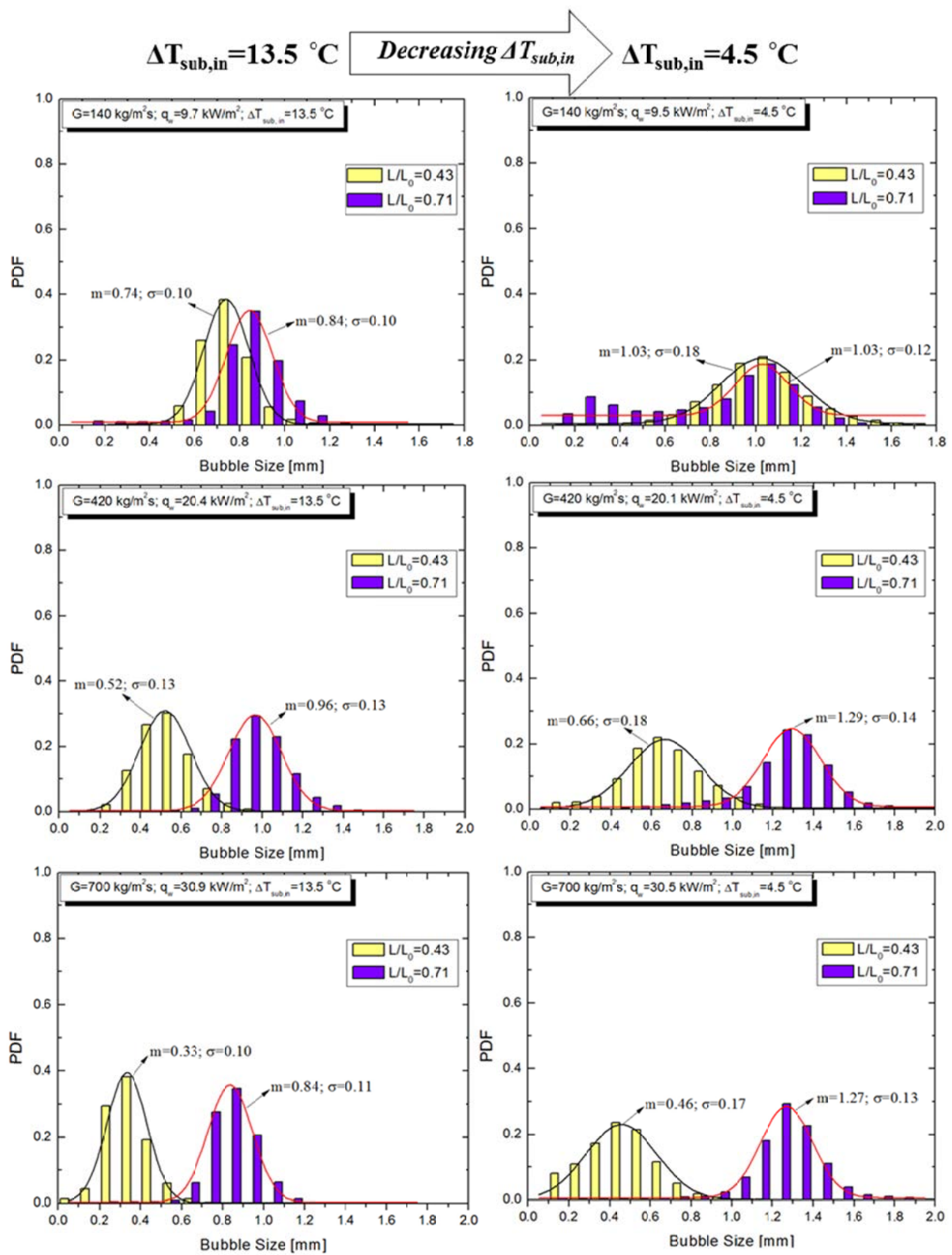

Figure 19. Effects of inlet subcooling $\left(\Delta \mathrm{T}_{\text {sub,in }}\right)$ on probability density function (PDF) for bubble size and its development in the upward flow direction 

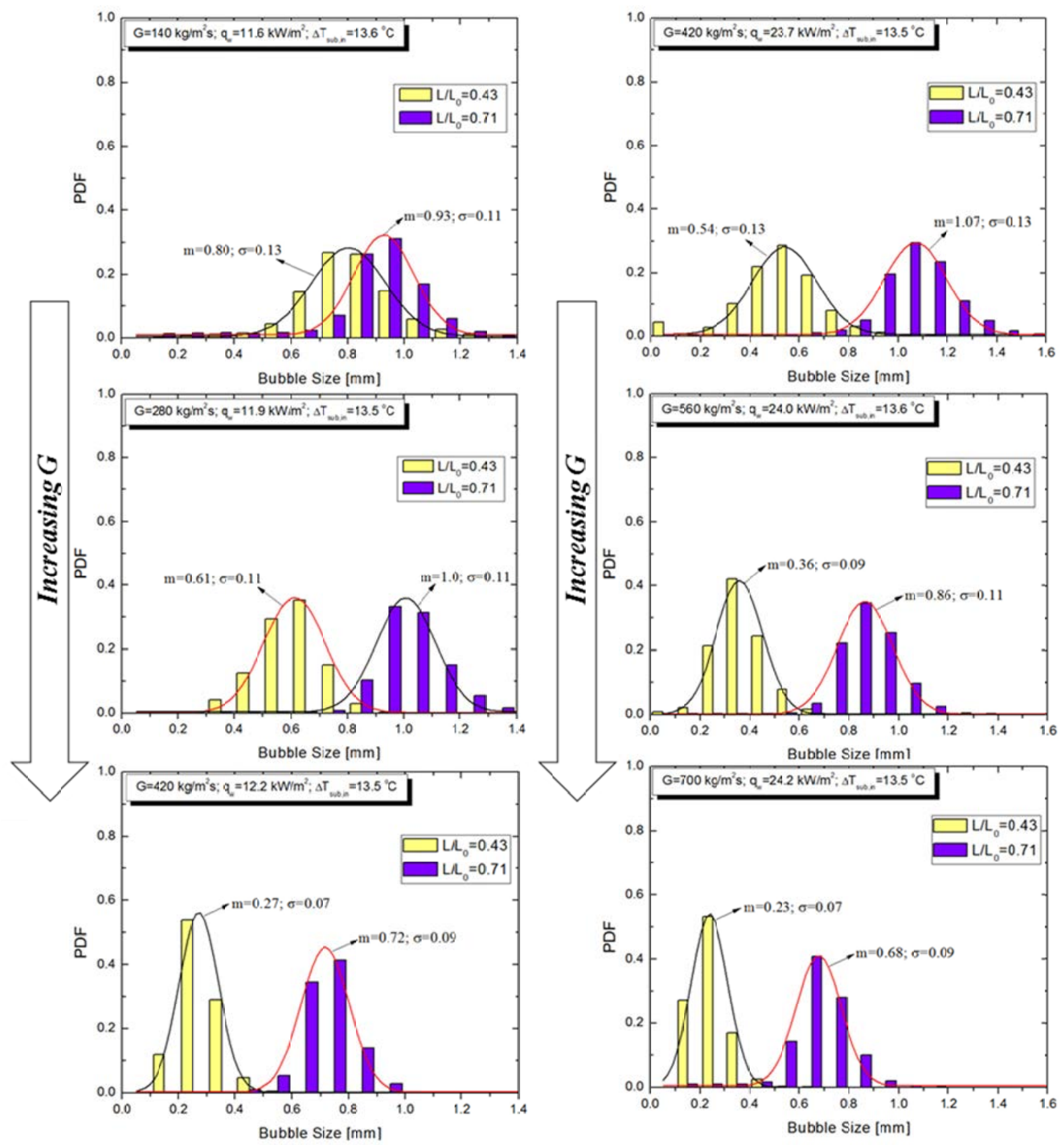

Figure 20. Effects of mass flux (G) on probability density function (PDF) for bubble size and its development in the upward flow direction 


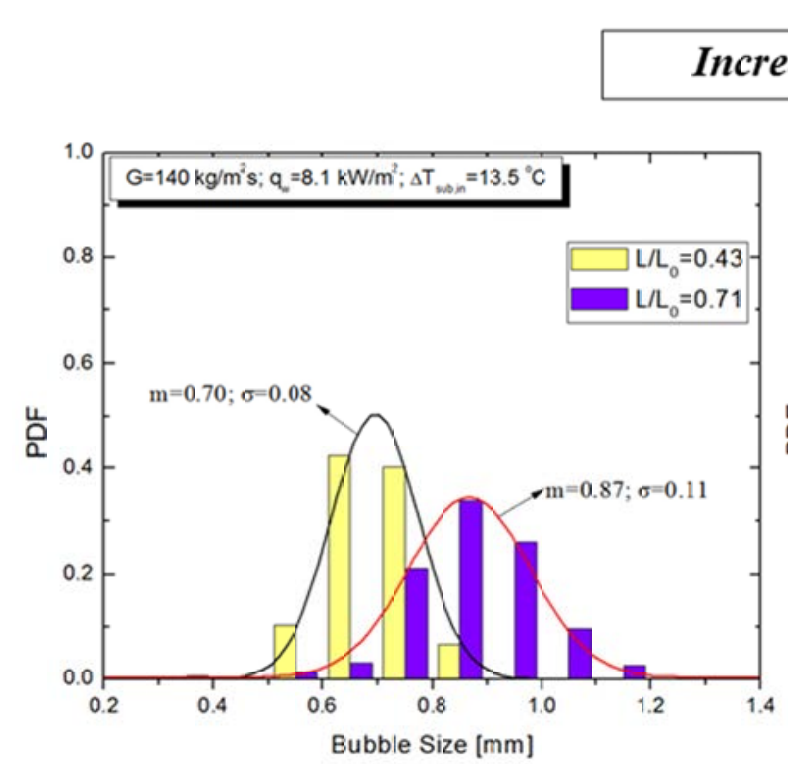

Increasing $q_{w}$
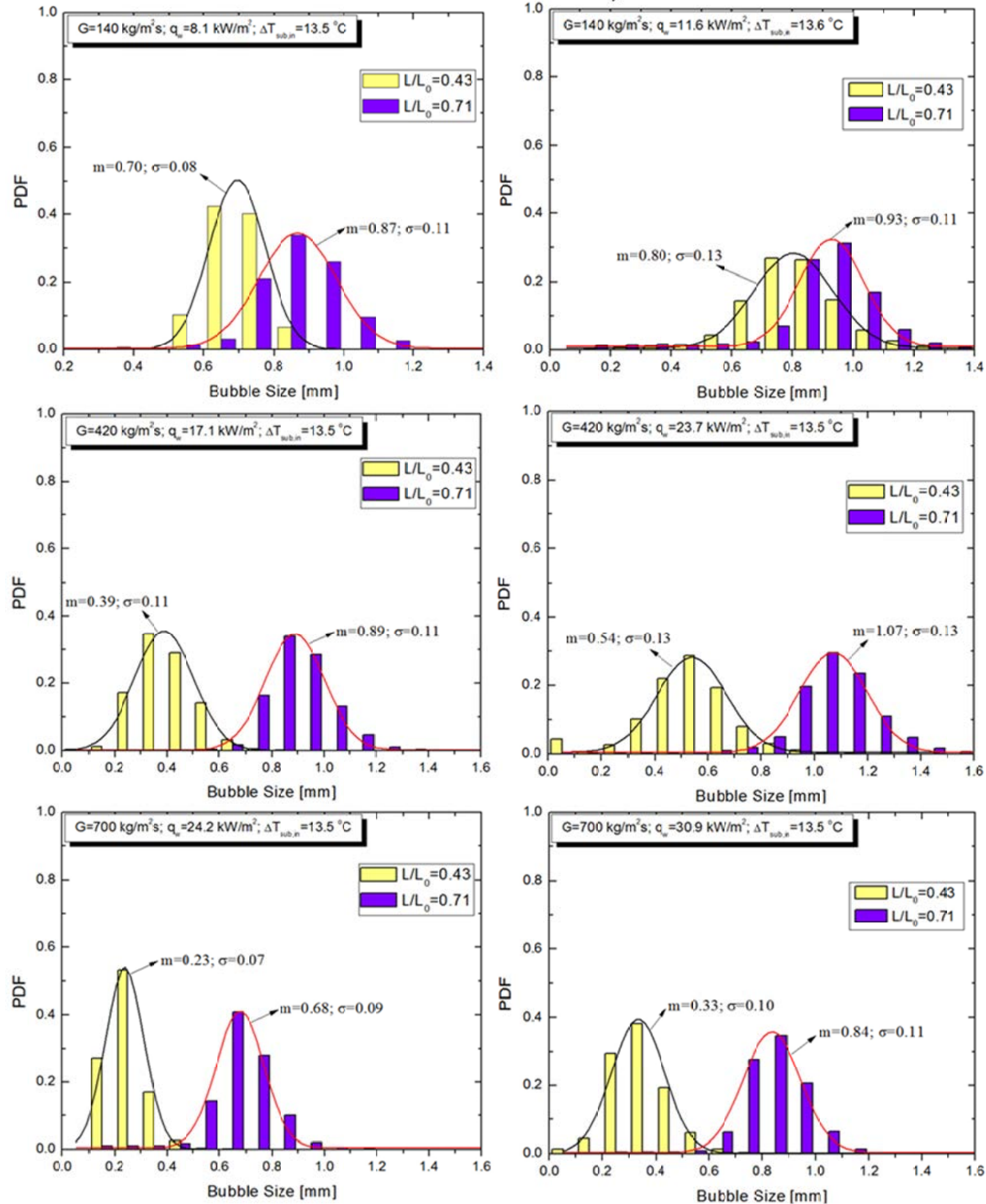

Figure 21. Effects of wall heat flux $\left(\mathrm{q}_{\mathrm{w}}\right)$ on probability density function (PDF) for bubble size and its development in the upward flow direction 
4. Effects of sliding bubbles on wall heat transfer

In the previous sections, sliding bubble characteristics within subcooled flow boiling channel were investigated in various aspects, for which large data set were collected and analyzed to achieve reliable statistics ${ }^{\mathrm{A}}$. In this section, wall heat transfer associated with such sliding bubbles motion is discussed based on the wall temperature measurement using IR thermometry. Our specific interest is the enhancement of wall heat transfer due to sliding bubbles which originated from the single nucleation site. For this study, the time-averaged wall heat transfer coefficients along the heater wall (total heated area: $7.5 \times 224 \mathrm{~mm}^{2}$ ) were estimated as follows:

$$
\mathrm{q}_{\mathrm{w}}(\mathrm{y})=\mathrm{H}\left[\mathrm{T}_{\mathrm{w}}(\mathrm{y})-\mathrm{T}_{1}(\mathrm{y})\right]
$$

where $H$ is the time-averaged wall heat transfer coefficient; $T_{w}(y)$ and $T_{1}(y)$ are the average wall temperature over the heater width $(7.5 \mathrm{~mm})$ and the bulk liquid temperature, both at the axial location $\mathrm{y}$, respectively; and $\mathrm{q}_{\mathrm{w}}(\mathrm{y})$ is the local wall heat flux entering the fluid. $\mathrm{T}_{\mathrm{w}}(\mathrm{y})$ and $\mathrm{q}_{\mathrm{w}}(\mathrm{y})$ were obtained by averaging the measured data from IR thermometry during the measurement period of $20 \mathrm{sec}$ (recording speed: $0.1 \mathrm{kHz})^{\mathrm{A}}$ while $\mathrm{T}_{1}$ was estimated by assuming that the total heat entering the fluid was eventually used to raise the bulk liquid temperature. Also, it is noted that the thermal resistance of ITO (heating film) may depend on the temperature ${ }^{\mathrm{A}}$, which may subsequently affect the local heat fluxes $\mathrm{q}_{\mathrm{w}}(\mathrm{y})$ provided to the fluid. To avoid the related issue, we evaluated $\mathrm{q}_{\mathrm{w}}(\mathrm{y})$ in Eq. (3) using the algorithm validated in our previous study (Yoo et al., 2015), instead of assuming the uniform wall heat flux ( $\mathrm{q}_{\mathrm{w}}$ ).

Also, for the present discussion, we defined the heated section upstream of the single nucleation site (i.e., $\left.0 \leq \mathrm{L} / \mathrm{L}_{0} \leq 0.41\right)$ as a single-phase $(1 \varnothing)$ heat transfer region while downstream (i.e., $\left.0.41<\mathrm{L} / \mathrm{L}_{0} \leq 1\right)$ was defined as a subcooled boiling or two-phase $(2 \varnothing)$ heat transfer region. Then, the transition from the single-phase heat transfer to the subcooled boiling heat transfer can be clearly identified by the abrupt increase in wall heat transfer coefficient along the flow path as shown in Figures 22. A typical wall temperature profile induced by the existence of a single nucleation site during this study can be seen in Part 1 paper ${ }^{\mathrm{A}}$.

As discussed in section 2, present boiling loop was configured to ensure that the flow was fully developed hydro-dynamically before entering the test channel. However, in most cases, the flow was still thermally developing until it reached the axial location of the single nucleation site $\mathrm{L} / \mathrm{L}_{0} \approx 0.41$. For this reason, we can often find in Figure 22 slightly decreasing heat transfer coefficient along the flow path, rather than a constant value at the region upstream of the nucleation site. 
In Figure 22, we can commonly see that the wall heat transfer coefficient sharply increased once the boiling was initiated at $\mathrm{L} / \mathrm{L}_{0} \approx 0.41$, but the amount of increase varied substantially depending on the specific test conditions. Also, the flow became thermally fully developed quite fast once boiling was initiated. In order to quantify the impact of sliding bubbles on the enhancement of wall heat transfer, we introduce the ratio $\mathrm{H}_{2 \varnothing} / \mathrm{H}_{1 \varnothing}$, in which $\mathrm{H}_{1 \varnothing}$ denotes the single-phase heat transfer coefficient measured upstream of the nucleation site, i.e., at $\mathrm{L} / \mathrm{L}_{0} \approx 0.4$ and $\mathrm{H}_{2 \varnothing}$ is the subcooled boiling heat transfer coefficient measured downstream at $\mathrm{L} / \mathrm{L}_{0} \approx 0.90$.

On the top two figures in Figure 22, time-averaged wall heat transfer coefficients are compared for the two subcooling conditions (i.e., $\Delta \mathrm{T}_{\text {sub,in }}=4.5$ and $13.5^{\circ} \mathrm{C}$ ); the parametric tests performed at lower $\mathrm{G}$ are shown on the left while those performed at higher $\mathrm{G}$ are shown on the right. It can be seen that $\mathrm{H}_{2 \varnothing} / \mathrm{H}_{1 \varnothing}$ increased as $\Delta \mathrm{T}_{\text {sub,in }}$ decreased. This implies that the bubble-induced heat transfer modes such as evaporation, quenching and liquid mixing due to sliding bubbles played a relatively more important role as $\Delta \mathrm{T}_{\text {sub,in }}$ decreased. About this, it is noted that sliding bubble size as well as sliding bubble velocity increased by decreasing $\Delta \mathrm{T}_{\text {sub,in }}$, as shown in Figures 3 and 5 (top) and Figures 15 and 16 (top). Also, as discussed in section 3.2.1, bubble release frequency tended to increase as well by decreasing $\Delta \mathrm{T}_{\text {sub,in }}$. Taken together, all the observed bubble characteristics depending on $\Delta \mathrm{T}_{\text {sub,in }}$ can explain qualitatively why the lower $\Delta \mathrm{T}_{\text {sub,in }}\left(=4.5^{\circ} \mathrm{C}\right)$ caused the higher value of $\mathrm{H}_{2 \varnothing} / \mathrm{H}_{1 \varnothing}$ in Figure 22 (top). 

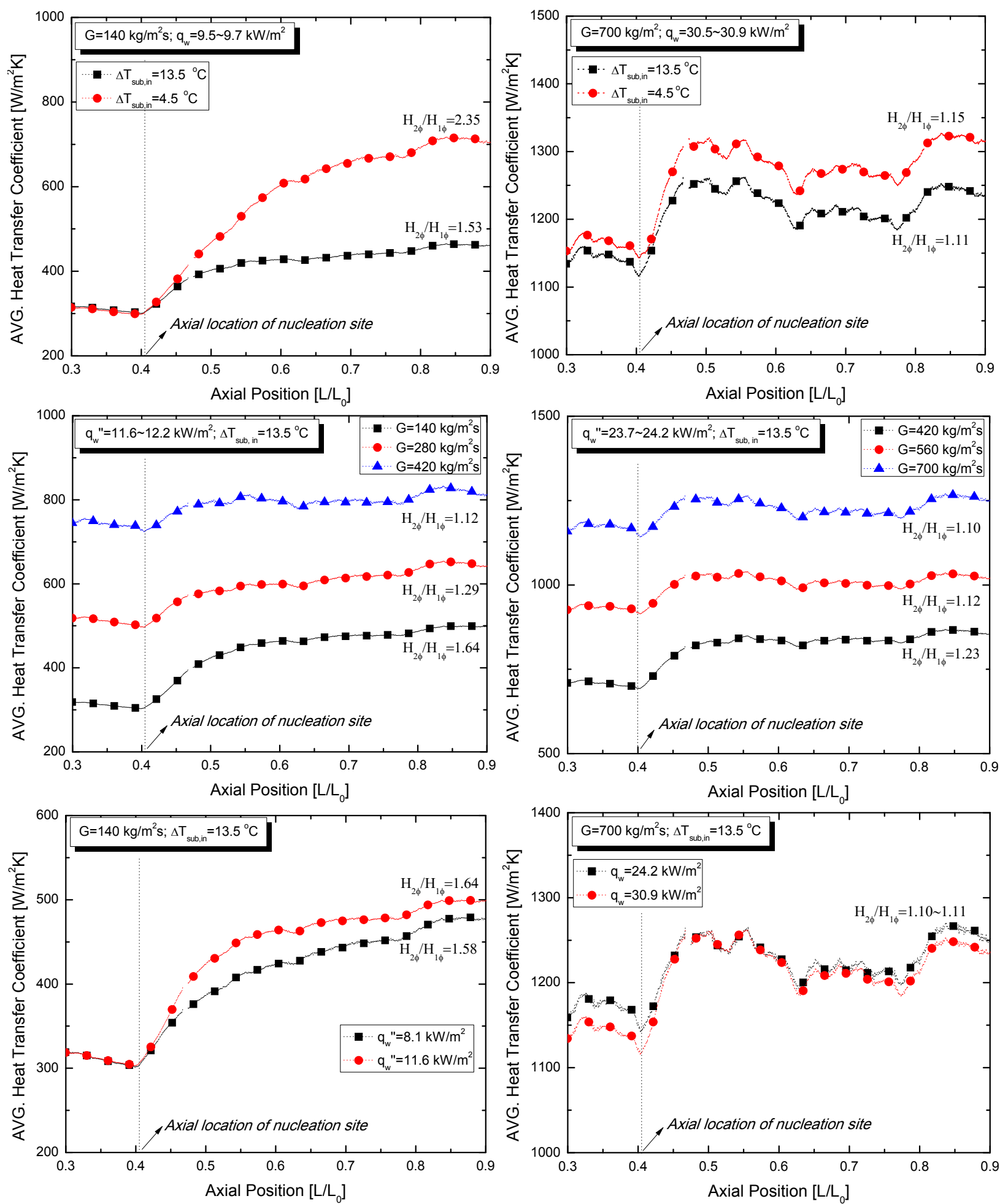

(At lower G conditions)

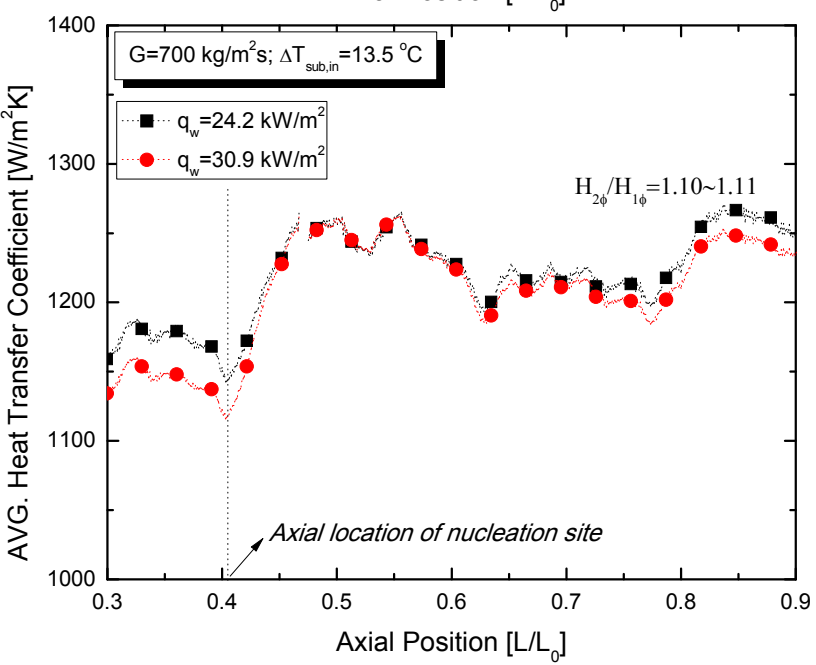

(At higher $\mathbf{G}$ conditions)

Figure 22. Effects of $\Delta \mathrm{T}_{\text {sub,in }}$ (top), $\mathrm{G}$ (middle), $\mathrm{q}_{\mathrm{w}}$ (bottom) on time-averaged wall heat transfer coefficient due to sliding bubbles 
In the middle of Figure 22 (both left and right sides), it can be seen that the wall heat transfer coefficients increased on the whole as $\mathrm{G}$ increased, as expected. However, the $\mathrm{H}_{2 \varnothing} / \mathrm{H}_{1 \varnothing}$ decreased as $\mathrm{G}$ increased. As discussed in section 3.1 the increase in $\mathrm{G}$ restricted more the bubble growth while sliding, especially near the nucleation site (see Figures 3 and 5 middle left). In section 3.3.1, we also discussed that the sliding bubble velocity near the nucleation site became lower as $\mathrm{G}$ increased (see the middle of Figures 15 and 16). Thus, we can associate these observations with the decreasing $\mathrm{H}_{2 \varnothing} / \mathrm{H}_{1 \varnothing}$ as $\mathrm{G}$ increased. In addition, we argued in section 3.2.1 that the relative significance of bubble-induced heat transfer modes, which corresponds to $\mathrm{H}_{2 \varnothing} / \mathrm{H}_{1 \varnothing}$, will deteriorate as $\mathrm{G}$ increases while the single-phase forced convection increases its effect. This argument is also well supported by the results shown in Figure 22 (middle). Additionally, it is noted that the abrupt increase in wall heat transfer always occurred within the region relatively near the nucleation site while the variation downstream was insignificant. Even when the varying trend of sliding bubble size or bubble velocity influenced by G were reversed downstream as observed in section 3.1.2 and 3.3.1, such effects did not critically affect the wall heat transfer at the downstream region. This implies that the bubble characteristics observed near the nucleation site played a dominant role in determining the ultimate level of wall heat transfer improvement within the test channel.

The bottom of Figure 22 (both left and right sides) shows the effect of $\mathrm{q}_{\mathrm{w}}$ on time-averaged wall heat transfer coefficient. On the left side, $\mathrm{H}_{2 \varnothing} / \mathrm{H}_{1 \varnothing}$ increased slightly as $\mathrm{q}_{\mathrm{w}}$ increased. This is likely due to the fact that the sliding bubbles became larger and moved faster while increasing $\mathrm{q}_{\mathrm{w}}$ as shown in section 3.1.2 (see Figures 3 and 5 bottom) and section 3.3.1 (see Figures 15 and 16 bottom). That is, bubble-induced heat transfer modes increased its significance by increasing $\mathrm{q}_{\mathrm{w}}$, resulting in higher $\mathrm{H}_{2 \varnothing} / \mathrm{H}_{1 \varnothing}$. However, on the right side of Figure 22 (bottom), noticeable change in $\mathrm{H}_{2 \varnothing} / \mathrm{H}_{1 \varnothing}$ depending on $\mathrm{q}_{\mathrm{w}}$ is not found.

To discuss the relation between bubble characteristics and $\mathrm{H}_{2 \varnothing} / \mathrm{H}_{1 \varnothing}$ in a more quantitative way, further analyses were performed as shown in Figures 23 and 24. Figure 23 clearly shows that the effect of sliding bubbles on wall heat transfer (i.e., $\left.\mathrm{H}_{2 \varnothing} / \mathrm{H}_{1 \varnothing}\right)$ increased as the absolute values of $\mathrm{u}_{\mathrm{r}}\left(\left|\mathrm{u}_{\mathrm{r}}\right|\right)$ increased (see the definition in Eq. (2); and note that $\left|\mathrm{u}_{\mathrm{r}}\right|$ shown in Figure 23 was obtained through averaging over the flow path $0.42<\mathrm{L} / \mathrm{L}_{0}<0.72$ ).

In case of sliding bubble size, however, the direct relation between the average bubble size over the flow path observed and $\mathrm{H}_{2 \varnothing} / \mathrm{H}_{1 \varnothing}$ was hard to find. Thus, we evaluated the average sliding bubble size at different regions separately, i.e., near the nucleation site $\left(0.41<\mathrm{L} / \mathrm{L}_{0}<0.45\right)$ and downstream $\left(0.5<\mathrm{L} / \mathrm{L}_{0}<0.72\right)$, and compared them with $\mathrm{H}_{2 \varnothing} / \mathrm{H}_{1 \varnothing}$ as shown on the left of Figure 24. The results show that $\mathrm{H}_{2 \varnothing} / \mathrm{H}_{1 \varnothing}$ and the average bubble size measured 
near the nucleation site had proportional relation, whereas no clear relation was found between $\mathrm{H}_{2 \varnothing} / \mathrm{H}_{1 \varnothing}$ and the average bubble size measured downstream. This implies that, despite the complex growth behavior of sliding bubbles (e.g., sliding peak), the characteristics observed near the nucleation site were primarily related to the ultimate level of wall heat transfer enhancement within the test channel.

On the right of Figure 24, we also investigate the relation between $\mathrm{H}_{2 \varnothing} / \mathrm{H}_{1 \varnothing}$ and effective bubble frequency

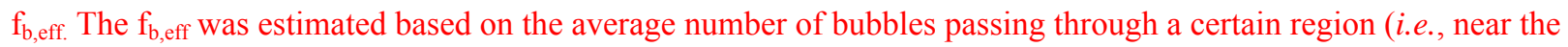
nucleation site and downstream) over the measurement time. However, no clear relation was found, implying that the $\left|\mathrm{u}_{\mathrm{r}}\right|$ and the sliding bubble size near the nucleate site were more dominant factors determining $\mathrm{H}_{2 \varnothing} / \mathrm{H}_{1 \varnothing}$.

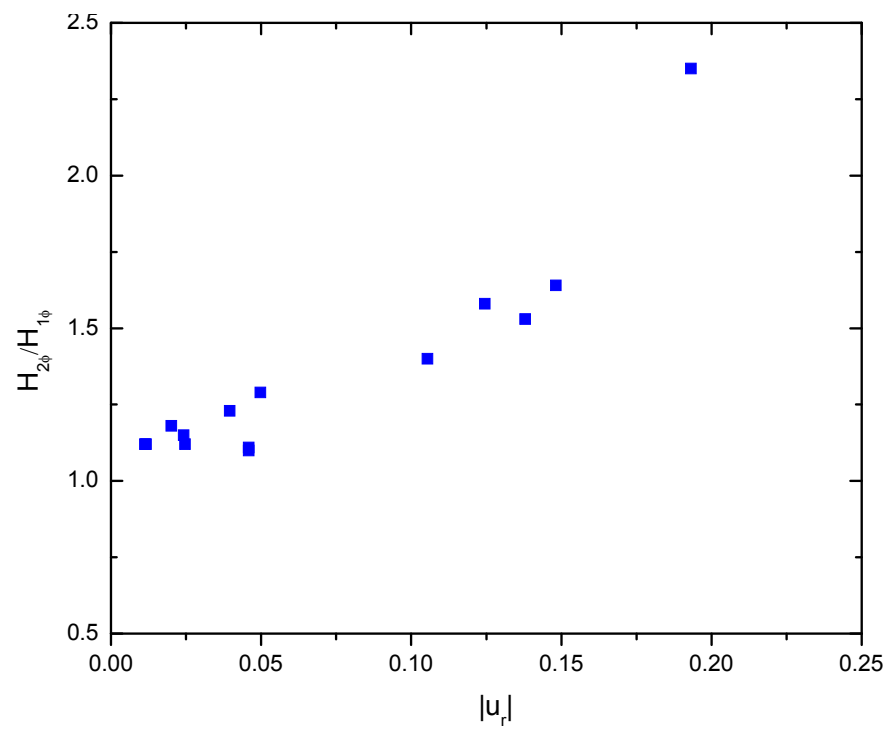

Figure 23. Experimentally observed relation between $\mathrm{H}_{2 \varnothing} / \mathrm{H}_{1 \varnothing}$ and $\left|\mathrm{u}_{\mathrm{r}}\right|$ 

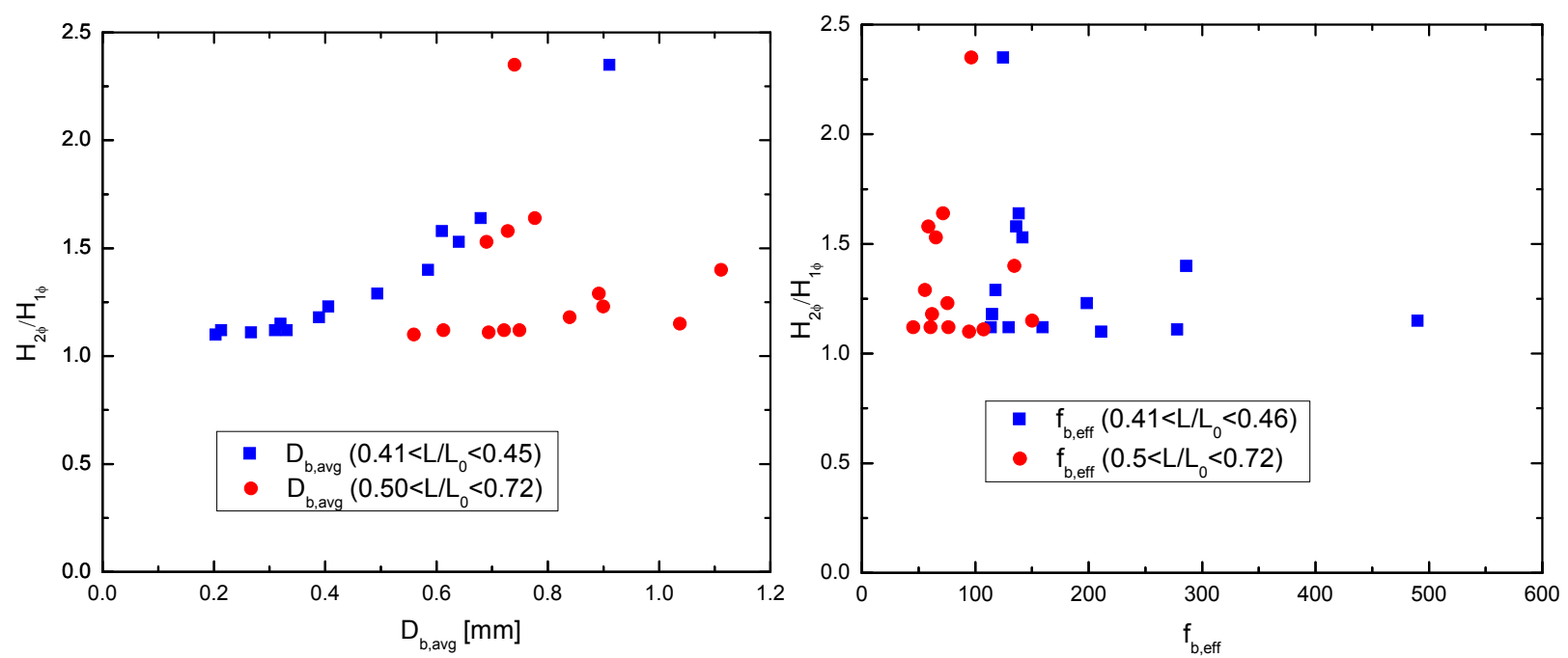

Figure 24. Experimentally observed relation between $\mathrm{H}_{2 \varnothing} / \mathrm{H}_{1 \varnothing}$ and sliding bubble size (left), effective sliding bubble frequency (right)

\section{Summary and conclusions}

Subsequent to Part 1 study ${ }^{\mathrm{A}}$ describing the experimental methods/strategies as well as the overall data quality achieved from the present subcooled flow boiling experiment, the specific experimental results for a variety of bubble and wall heat transfer parameters are discussed in this paper. The major findings and conclusions are summarized as follows.

\section{Bouncing motion of bubbles}

Bubbles typically bounced after departure from the nucleation site before sliding, causing a bouncing peak of bubble size. The bouncing motion of bubbles became more noticeable at the test conditions causing higher wall temperature by decreasing $\Delta \mathrm{T}_{\text {sub,in }} / \mathrm{G}$ or increasing $\mathrm{q}_{\mathrm{w}}$. Also, the bubbles were more likely to be deformed at the test conditions involving more bouncing bubbles.

\section{Bubble growth behavior while sliding}

Sliding bubbles showed two distinct growth behavior: (i) at lower mass flux $(\mathrm{G})$, sliding bubbles' growth behavior was largely fluctuating with a sliding peak; bubbles grew fast near the nucleation site, subsequently shrank, and then grew slowly again, (ii) however, as $\mathrm{G}$ increased, the sliding peak was reduced, i.e., sliding bubbles grew more steadily. Also, it was found that the sliding peak resulted from the sharp decrease in sliding bubble growth rate 
from positive to negative values after the bubbles departed from the nucleation site. The sliding peak significantly influenced the bubble growth behavior downstream. Specifically, the effect of $\Delta \mathrm{T}_{\text {sub,in }}, \mathrm{G}$, and $\mathrm{q}_{\mathrm{w}}$ on sliding bubble size observed upstream often became reduced or even reversed after the sliding peak.

\section{Bubbles release frequency}

The average bubble release frequency often varied inconsistently relative to changes in $\Delta \mathrm{T}_{\text {sub,in }}, \mathrm{G}$, and $\mathrm{q}_{\mathrm{w}}$. We contend that the competing process between single-phase forced convection and bubble-induced heat transfer modes (i.e., evaporation and quenching) was the major reason causing such inconsistency. Also, the performance of existing bubble departure frequency models were tested based on the present data.

\section{Coalescence of sliding bubbles}

The sliding bubbles which originated from a single nucleation site coalesced frequently. Also, the coalescence frequency increased (i.e., more decrease in bubble number) near the nucleation site at the test cases involving higher bubble release frequency. However, for such cases involving significant coalescence of sliding bubbles near the nucleation site, the coalescence frequency was substantially reduced downstream.

\section{Sliding bubbles velocity}

Near the nucleation site, sliding bubbles always moved faster as the bubble size increased by decreasing $\Delta \mathrm{T}_{\text {sub,in }} / \mathrm{G}$ or by increasing $\mathrm{q}_{\mathrm{w}}$. However, during the parametric tests for $\mathrm{G}$, such observation often became reversed as the bubbles moved downstream. This is because the effect of increasing $G$ on sliding bubble velocity varied

depending on the distance from the nucleation site. Specifically, the decrease in buoyancy by increasing G lowered the sliding bubbles' velocity near the nucleation site, whereas the interfacial drag led to the increase in sliding bubble velocity downstream as $\mathrm{G}$ increased. Also, at low $\mathrm{G}$ the sliding bubbles moved faster than the local liquid (i.e., $\mathrm{u}_{\mathrm{r}}<0$ ), while such difference became reversed as $\mathrm{G}$ increased (i.e., $\mathrm{u}_{\mathrm{r}}>0$ ).

\section{Statistical distribution of sliding bubble size and its axial development}

In most experimental cases, the PDFs for bubble size followed Gaussian distribution quite well both near and far from the nucleation site. At higher inlet subcooling $\left(\Delta \mathrm{T}_{\text {sub,in }} \approx 13.5^{\circ} \mathrm{C}\right)$, the standard deviation $(\sigma)$ of bubble 
size varied little while sliding along the flow path whereas more variations were found at lower inlet subcooling $\left(\Delta \mathrm{T}_{\text {sub,in }} \approx 4.5^{\circ} \mathrm{C}\right)$. However, such changes in $\sigma$ were insignificant compared to those in mean bubble size. Also, the $\sigma$ of bubble size tended to increase as the wall temperature increased by decreasing $\Delta \mathrm{T}_{\text {sub,in }} / \mathrm{G}$ or by increasing $\mathrm{q}_{\mathrm{w}}$.

\section{Time-averaged wall heat transfer coefficient}

The bubbles generated from a single nucleation site caused a significant increase in wall heat transfer while sliding. The enhancement of wall heat transfer relative to single-phase forced convection, i.e., $\mathrm{H}_{2 \varnothing} / \mathrm{H}_{1 \varnothing}$ increased as $\Delta \mathrm{T}_{\text {sub,in }} / \mathrm{G}$ decreased or $\mathrm{q}_{\mathrm{w}}$ increased. Also, the abrupt increase in wall heat transfer occurred within the region relatively near the nucleation site. In particular, the absolute value of relative bubble velocity $\left|\mathrm{u}_{\mathrm{r}}\right|$ and sliding bubble growth near the nucleate site was proved to play a dominant role in determining the ultimate level of wall heat transfer enhancement within the test channel.

The observations on various aspects of bubble and wall heat transfer characteristics in this study provided a number of experimental insights, which have not been discovered before, on the fundamentals of subcooled boiling flow. We expect that these experimental findings, which are based on reliable statistics, can be used to develop, validate, and improve the models for subcooled boiling flow. The next step research is to extend our understanding by acquiring experimental data under more complex boiling conditions such as multiple nucleation sites.

\section{Acknowledgment}

The authors acknowledge the support by CASL (Consortium for Advanced Simulation of Light Water Reactors) a DOE Energy Innovation Hub for this research. The support is gratefully acknowledged. 


\section{References}

Bae, B.-U., Yun, B.-J., Yoon, H.-Y., Song, C.-H., Park, G.-C., 2010. Analysis of subcooled boiling flow with onegroup interfacial area transport equation and bubble lift-off model. Nuclear Engineering and Design 240, $2281-2294$. Basu, N., Warrier, G.R., Dhir, V.K., 2005. Wall heat flux partitioning during subcooled flow boiling: Part 1-Model development. Journal of heat Transfer 127, 131-140.

Bowring, R.W., 1962. Physical model based on bubble detachment and calculation of steam voidage in the subcooled region of a heated channel. OECD Halden Reactor Project Report HPR-10.

Cheung, S., Vahaji, S., Yeoh, G., Tu, J., 2014. Modeling subcooled flow boiling in vertical channels at low pressures-Part 1: Assessment of empirical correlations. International Journal of Heat and Mass Transfer 75, 736753.

Chu, I.C., No, H.C., Song, C.H., 2011. Bubble lift-off diameter and nucleation frequency in vertical subcooled boiling flow. J Nucl Sci Technol 48, 936-949.

Cole, R., 1960. A photographic study of pool boiling in the region of the critical heat flux. AIChE Journal 6, 533538.

Cornwell, K., 1990. The influence of bubbly flow on boiling from a tube in a bundle. Int J Heat Mass Tran 33, 25792584.

Delvalle, V.H., Kenning, D.B.R., 1985. Subcooled flow boiling at high heat-flux. Int J Heat Mass Tran 28, 19071920.

Euh, D., Ozar, B., Hibiki, T., Ishii, M., Song, C.-H., 2010. Characteristics of bubble departure frequency in a lowpressure subcooled boiling flow. Journal of nuclear science and technology 47, 608-617.

Forster, H.K., Greif, R., 1959. Heat transfer to a boiling liquid - mechanisms and correlations. J Heat Trans-T Asme 81, 43-53.

Hibiki, T., Ishii, M., 2003. Active nucleation site density in boiling systems. Int J Heat Mass Tran 46, $2587-2601$. Hibiki, T., Ishii, M., 2007. Lift force in bubbly flow systems. Chemical Engineering Science 62, 6457-6474. Houston, S.D., Cornwell, K., 1996. Heat transfer to sliding bubbles on a tube under evaporating and nonevaporating conditions. Int J Heat Mass Tran 39, 211-214.

Ishii, M., Zuber, N., 1979. Drag coefficient and relative velocity in bubbly, droplet or particulate flows. AIChE Journal 25, 843-855.

Ivey, H., 1967. Relationships between bubble frequency, departure diameter and rise velocity in nucleate boiling. International Journal of Heat and Mass Transfer 10, 1023-1040.

Klausner, J., Mei, R., Bernhard, D., Zeng, L., 1993. Vapor bubble departure in forced convection boiling. International journal of heat and mass transfer 36, 651-662.

Krepper, E., Rzehak, R., 2011. CFD for subcooled flow boiling: Simulation of DEBORA experiments. Nuclear Engineering and Design 241, 3851-3866.

Kurul, N., Podowski, M.Z., 1990. Multidimensional effects in forced convection subcooled boiling, Proceedings of the 9th International Heat Transfer Conference. Hemisphere Publishing Corporation, Jerusalem, Israel, pp. 21-26.

Li, S., Tan, S., Xu, C., Gao, P., Sun, L., 2013. An experimental study of bubble sliding characteristics in narrow channel. International Journal of Heat and Mass Transfer 57, 89-99.

Maity, S., 2000. Effect of velocity and gravity on bubble dynamics. UCLA.

Martinez-Cuenca, R., Brooks, C.S., Julia, J.E., Hibiki, T., Ishii, M., 2015. Stochastic nature of wall nucleation and its impact on the time average boundary condition. J Heat Trans-T Asme 137, 021504.

Okawa, T., Ishida, T., Kataoka, I., Mori, M., 2005. An experimental study on bubble rise path after the departure from a nucleation site in vertical upflow boiling. Exp Therm Fluid Sci 29, 287-294.

Prodanovic, V., Fraser, D., Salcudean, M., 2002. Bubble behavior in subcooled flow boiling of water at low pressures and low flow rates. International journal of multiphase flow 28, 1-19.

Ramstorfer, F., Breitschädel, B., Steiner, H., Breee, G., 2005. Modelling of the near-wall liquid velocity field in subcooled boiling flow, Proc. ASME Summer Heat Transfer Conf.

Sato, Y., Sadatomi, M., Sekoguchi, K., 1981. Momentum and heat transfer in two-phase bubble flow-I. Theory. International Journal of Multiphase Flow 7, 167-177.

Situ, R., Hibiki, T., Ishii, M., Mori, M., 2005. Bubble lift-off size in forced convective subcooled boiling flow. International Journal of Heat and Mass Transfer 48, 5536-5548.

Situ, R., Ishii, M., Hibiki, T., Tu, J., Yeoh, G.H., Mori, M., 2008. Bubble departure frequency in forced convective subcooled boiling flow. International Journal of Heat and Mass Transfer 51, 6268-6282.

Stuurman, N., 2003. MTrack2. http://valelab.ucsf.edu/ nstuurman/ijplugins/MTrack2.html. 
Takagi, S., 1995. Three dimensional calculation of a rising bubble, Proceedings of the Second International Conference on Multiphase Flows (Tokyo).

Thorncroft, G.E., Klausner, J.F., 1999. The influence of vapor bubble sliding on forced convection boiling heat transfer. J Heat Trans-T Asme 121, 73-79.

Thorncroft, G.E., Klausner, J.F., Mei, R., 1998. An experimental investigation of bubble growth and detachment in vertical upflow and downflow boiling. Int J Heat Mass Tran 41, 3857-3871.

Tomiyama, A., 2004. Drag, lift and virtual mass force acting on a single bubble, 3rd International Symposium on Two-Phase Flow Modelling and Experimentation, 2004.

Troniewski, L., Ulbrich, R., 1984. Two-phase gas-liquid flow in rectangular channels. Chemical engineering science $39,751-765$.

Xu, J.J., Chen, B.D., Huang, Y.P., Yan, X., Yuan, D.W., 2013. Experimental visualization of sliding bubble dynamics in a vertical narrow rectangular channel. Nucl Eng Des 261, 156-164.

Yeoh, G., Cheung, S.C., Tu, J., Ho, M.K., 2008. Fundamental consideration of wall heat partition of vertical subcooled boiling flows. International Journal of Heat and Mass Transfer 51, 3840-3853.

Yoo, J., 2015. Experimental study on the subcooled boiling flow via optical measurement techniques, Ph.D dissertation. Texas A\&M University.

Yoo, J., Estrada-Perez, C.E., Hassan, Y.A., 2014. A proper observation and characterization of wall nucleation phenomena in a forced convective boiling system. International Journal of Heat and Mass Transfer 76, 568-584.

Yoo, J., Estrada-Perez, C.E., Hassan, Y.A., 2015. An accurate wall temperature measurement using infrared thermometry with enhanced two-phase flow visualization in a convective boiling system. Int J Therm Sci 90, 248266.

Yuan, D.W., Pan, L.M., Chen, D.Q., Zhang, H., Wei, J.H., Huang, Y.P., 2011. Bubble behavior of high subcooling flow boiling at different system pressure in vertical narrow channel. Appl Therm Eng 31, 3512-3520.

Yun, B.-J., Splawski, A., Lo, S., Song, C.-H., 2012. Prediction of a subcooled boiling flow with advanced two-phase flow models. Nuclear engineering and design 253, 351-359.

Zuber, N., 1959. Hydrodynamic aspects of boiling heat transfer (thesis). California. Univ., Los Angeles; and RamoWooldridge Corp., Los Angeles.

Zuber, N., 1963. Nucleate boiling. The region of isolated bubbles and the similarity with natural convection. Int J Heat Mass Tran 6, 53-78. 